\title{
Approaches to the Synthesis of Highly Substituted Aromatic and Fused Rings: The Metal Catalyzed Cyclisation Versus the Thermal Cyclisation
}

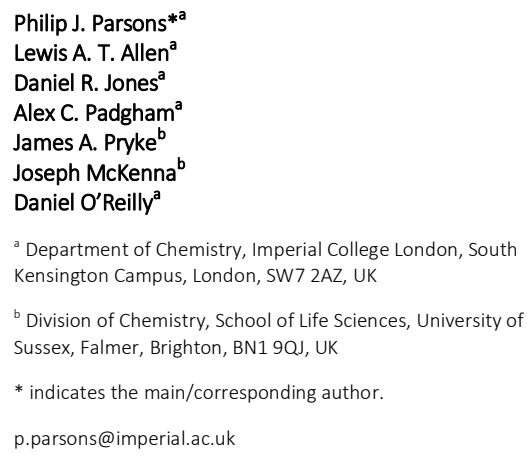

${ }^{a}$ Department of Chemistry, Imperial College London, South Kensington Campus, London, SW7 2AZ, UK

${ }^{\mathrm{b}}$ Division of Chemistry, School of Life Sciences, University of Sussex, Falmer, Brighton, BN1 9QJ, UK

* indicates the main/corresponding author.

p.parsons@imperial.ac.uk

Dedicated to Dr. Alfred Bader on the occasion of his 93rd birthday and in memory of Oxana Bennett

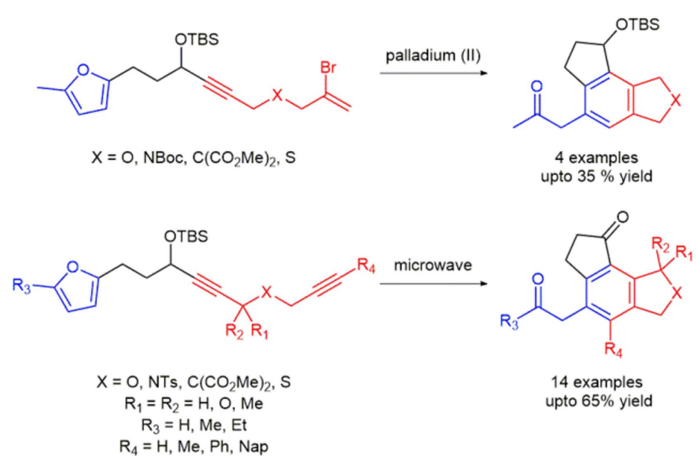

Received:
Accepted:
Published online:
DOI:

Abstract A domino reaction has been used for the construction of lactonamycin derivatives. This research led to a comparison study between palladium mediated cascade cyclisations and thermal alkyne $[2+2+2]$ cyclisations. A palladium mediated cyclisation of alkenyl bromides with alkynes and furans has been shown to furnish highly substituted aromatic rings. Penta and hexasubstituted aromatic rings have been also been prepared by the thermolysis of suitably substituted alkynes under microwave conditions. Tetrasubstituted pyridines can also be prepared using nitriles instead of alkynes. This work will provide a new and interesting array of drug templates; mechanistic details are discussed for both reaction series.

Key words alkynes, aromatic rings, cyclisation, thermolysis, palladium

Over the years domino reactions have been developed as powerful methods for the efficient synthesis of complex molecules, often of biological interest. ${ }^{1}$ Domino reactions entail at least two consecutive bond forming or bond rearrangement reactions where each following reaction relies on the chemistry involved in the preceding step. ${ }^{2}$ These time resolved sequences ${ }^{3}$ can be designed by carefully evaluating the functional group reactivity in the starting materials and as such they can be initiated using a variety of techniques, including photochemistry, ${ }^{4}$ radical chemistry, ${ }^{5}$ metal catalysis, ${ }^{6}$ organocatalysis, $^{7}$ and thermal cyclisations. ${ }^{8,9}$ Given the importance of aromatic polyfunctional arrays in the chemical industries, we sought to develop new domino processes for the preparation of the aforementioned ring systems. This paper is concerned with the evaluation of the scope and limitations of our domino process for the preparation of polysubstituted aromatic rings. A palladium mediated cyclisation together with a thermal approach for the formation of functionalized aromatic rings are compared.
In 2006, model studies were developed that could be applied to the synthesis of lactonamycin (Figure 1). Other interesting fused heterocyclic and carbocyclic fused ring systems could also be formed under the cyclisation conditions. ${ }^{10}$

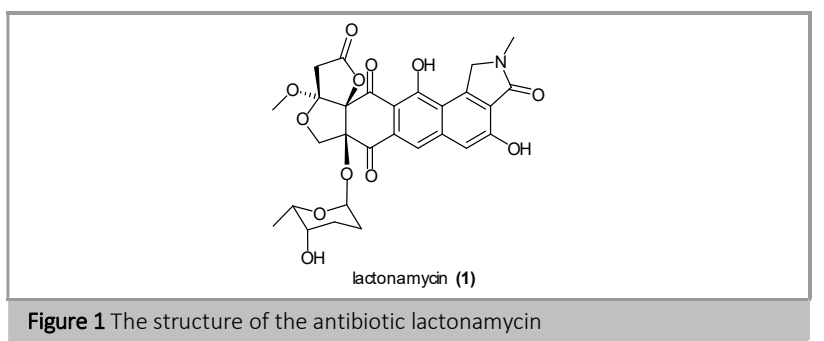

Initially, a tin mediated radical cyclisation had been envisioned to convert amide $\mathbf{2}$ to the tetracycle $\mathbf{3}$. Early investigations however led to the unexpected tetracycle 4 in 14\% yield when the alkenyl bromide $\mathbf{2}$ was treated with tin hydride and AIBN in refluxing benzene (Scheme 1).

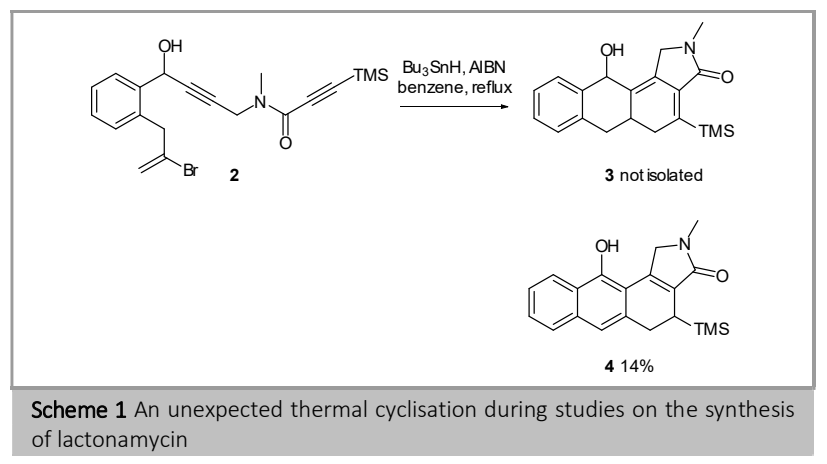


Thermal degradation studies were undertaken to determine the stability of the alkenyl bromide 2 . It was found that in the absence of tin hydride the substrate 2 provided the lactam 4 in improved yields for almost all of the investigated solvents (Table 1).

\begin{tabular}{|l|l|l|l|}
\hline \multicolumn{2}{|l|}{ Table 1 Decomposition studies } \\
\hline Entry & Solvent & Reaction Time (hr) & Yield (\%) \\
\hline 1 & Benzene & 48 & 26 \\
\hline 2 & THF & 144 & 35 \\
\hline 3 & Toluene & 2 & 41 \\
\hline 4 & DMF & 0.5 & 63 \\
\hline 5 & Diglyme & 0.5 & 23 \\
\hline 6 & DMSO & 0.25 & decomposition \\
\hline
\end{tabular}

The significant difference between the yields for DMF and toluene was attributed to the known decomposition of DMF to dimethylamine and carbon monoxide. It was hypothesized that the dimethylamine produced during the decomposition of DMF scavenged hydrobromic acid produced during the reaction. Based upon this hypothesis and Corey's work on gibberellic acid, ${ }^{11}$ we decided to investigate the use an acid trap. When 1,2epoxyhexane was added to the reaction mixture, the tetracyclic product 4 was isolated in an improved yield of $76 \%$ (Scheme 2).

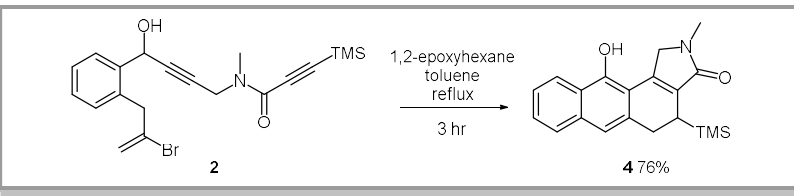

Scheme 2 Unexpected cyclisation to provide 4

We have since shown that the core of the antibiotic lactonamycin can be constructed in one synthetic operation in $73 \%$ yield from the amide 8 using this strategy (Scheme 3).12 of key importance in the synthesis of the cyclisation substrate is the use of the Knochel-Hauser base ${ }^{13}$ which provided 8 in $60 \%$ yield from the aldehyde 6 . The use of tert-butyl bromide, a neutral proton source, in the workup was also important to the success of this reaction; other proton sources had adverse effects on the yield.

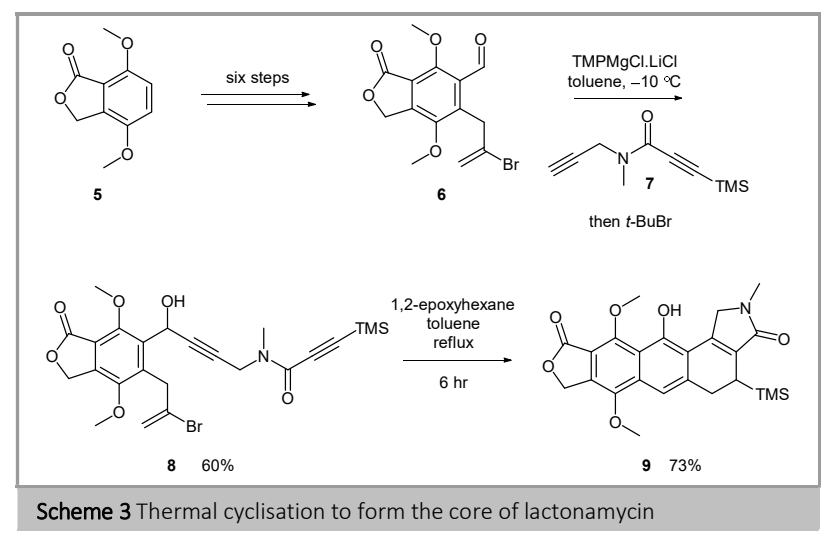

Further investigations to extend our original findings were carried out (Scheme 4).9,14 It was found that both the amide 10 and ester $\mathbf{1 1}$ cyclisation precursors cyclized to their respective furan products $\mathbf{1 2}$ and 13. There is however a significant difference in the rate of reaction between the two substrates. The difference in rate of reaction can be rationalized by considering the relative populations of the reactive conformers: there is a lower population of the cisoid conformer for the ester than for the amide.

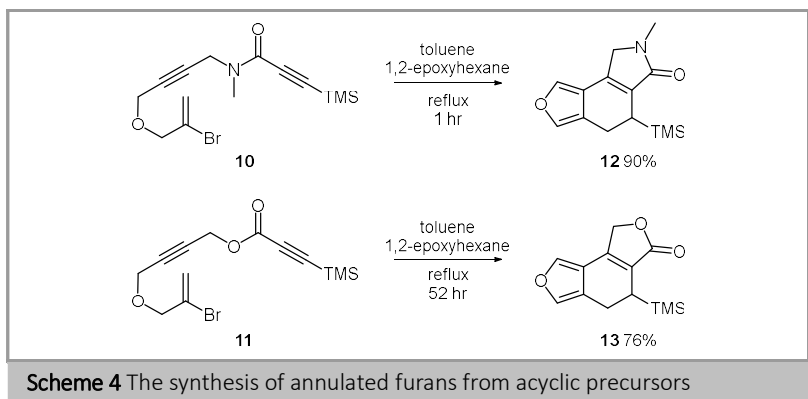

Thus far, we have used ester and amide substrates for the cyclisation reaction. In view of the importance of fused all carbon rings in chemical research, we examined the possibility of using our cascade sequence for the formation of functionalized steroid mimics; for this purpose the ketone substrate 18 was prepared (Scheme 5). Conversion of the known alcohol $\mathbf{1 4}$ to the ether $\mathbf{1 5}$ proceeded smoothly with sodium hydride and 2,3-dibromopropene. The silyl protecting group was removed with TBAF and the resulting alcohol $\mathbf{1 6}$ was oxidized under Swern conditions to provide the aldehyde $\mathbf{1 7}$. Addition of lithium trimethylsilylacetylide to $\mathbf{1 7}$ formed, after work up, a propargylic alcohol, which was then oxidized with Dess-Martin periodinane to form the ketone $\mathbf{1 8 .}$

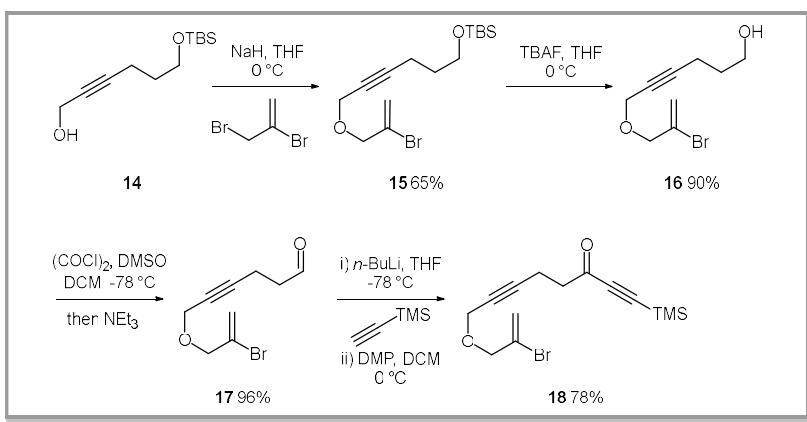

\section{Scheme 5 Synthesis of the thermal cyclisation precursor 18}

In boiling toluene, the ketone precursor $\mathbf{1 8}$ cyclized over four days to form the cyclopentenone 19 in $62 \%$ yield (Scheme 6). The alkyne $\mathbf{2 0}$ was also formed in $11 \%$ yield during the reaction through protodesilylation of the starting material due to the prolonged heating.

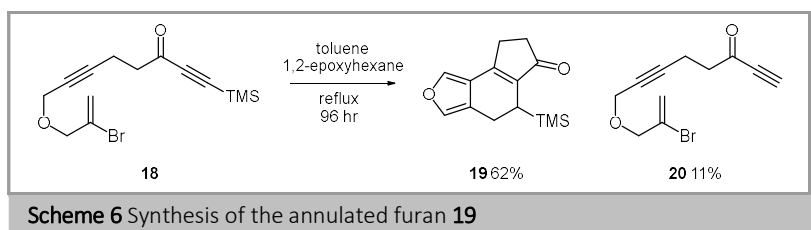


To suppress the formation of the alkyne $\mathbf{2 0}$, microwave heating was investigated. As expected, the shorter reaction time suppressed the formation of the alkyne for all solvents investigated. The reaction duration in toluene was substantially reduced from 96 hours to 2 hours for a comparable yield (Entry 3, Table 2). DMF, acetonitrile, and DCE all provided the product 19 in a marginally lower yield than toluene. In line with our previous results (Entry 6, Table 1), DMSO caused complete decomposition of the cyclisation substrate. Given DCE's more favourable volatility and microwave absorption properties when compared to toluene, 15 a higher temperature run was conducted. Cyclisation of the ketone substrate 18 at $200{ }^{\circ} \mathrm{C}$ provided the expected product $\mathbf{2 8}$ in an improved $81 \%$ yield (Entry 8, Table 2).

Table 2 Microwave synthesis of 19

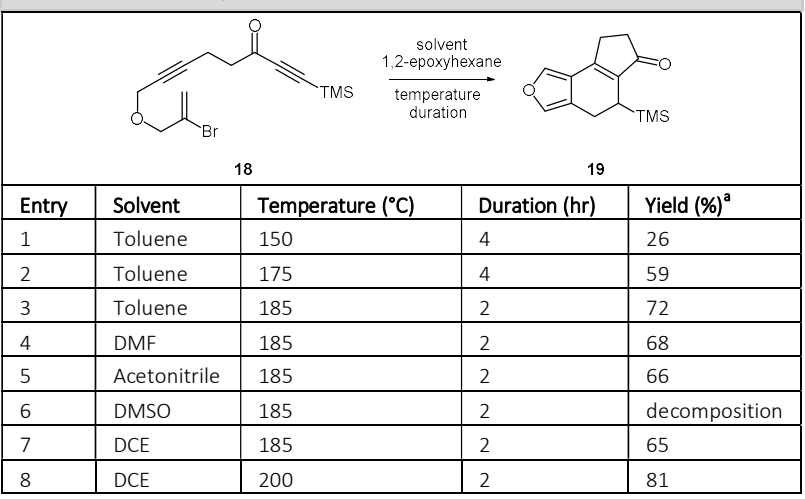

${ }^{a}$ For all entries, the alkyne 20 was not observed

We had previously prepared the homologue of the cyclisation substrate $\mathbf{2 1}$ from 5-hexyn-1-ol using the chemistry described in scheme 5. Unfortunately after 4 days in boiling toluene, there was no evidence of the cyclized product 22 by ${ }^{1} \mathrm{H}$ NMR. With microwave conditions in hand, the cyclisation of $\mathbf{2 1}$ was reinvestigated at the higher temperature of $200{ }^{\circ} \mathrm{C}$ with no success (Scheme 7). This result can be rationalised by considering the increase in the degrees of freedom of ketone $\mathbf{2 1}$ relative to the successful substrate 18. Notably, the dioxolane 23, prepared by protection of $\mathbf{1 8}$, was also unsuccessful under both conventional and microwave heating.

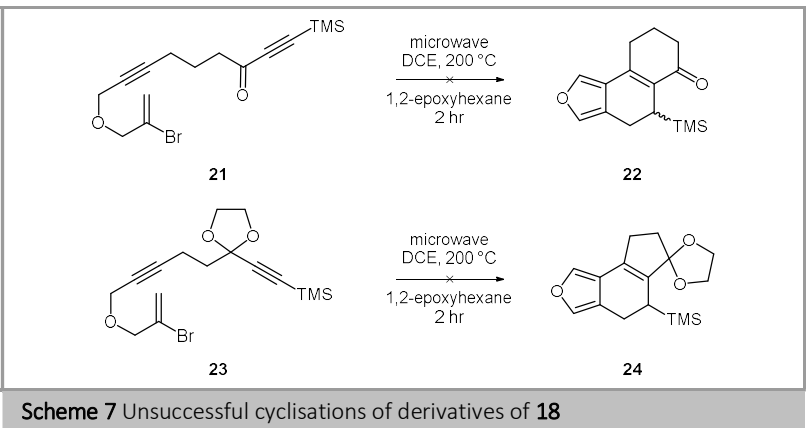

With optimised microwave conditions in hand for the synthesis of the annulated furan 19, the synthesis of pyrrole and thiophene analogues was investigated. The previously prepared alcohol 14 was chosen as a convenient point to form the amine and sulphide examples. The alcohol $\mathbf{1 4}$ was converted to the free amine 26 through a modified Gabriel amine synthesis. Allylation of the primary amine $\mathbf{2 6}$, followed by tosyl protection gave intermediate $\mathbf{2 8}$ (Scheme 8).

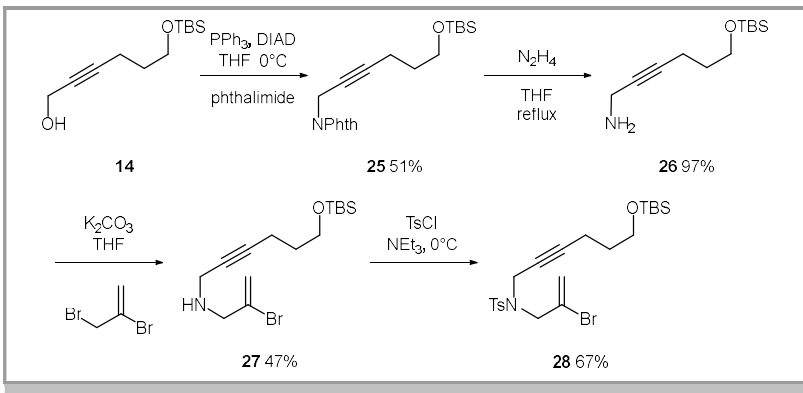

Scheme 8 Preparation of nitrogen 28 derivative of the ether 15

The sulphide $\mathbf{3 0}$ was prepared using a two step sequence. A Mitsunobu reaction provided the thioester 29, which was deprotected and then allylated in situ to give $\mathbf{3 0}$ (Scheme 9).

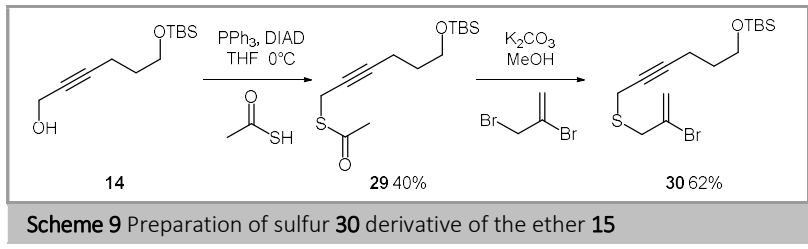

The synthetic sequence for $\mathbf{1 4}$ to $\mathbf{1 8}$ (Scheme 5) was used to provide the cyclisation precursors $\mathbf{3 1}$ and $\mathbf{3 2}$ from the protected alcohols $\mathbf{2 8}$ and $\mathbf{3 0}$. When the substrates were heated in a microwave reactor, the expected pyrrole $\mathbf{3 3}$ and thiophene $\mathbf{3 4}$ products were formed in $61 \%$ and $58 \%$ yields respectively (Scheme 10).

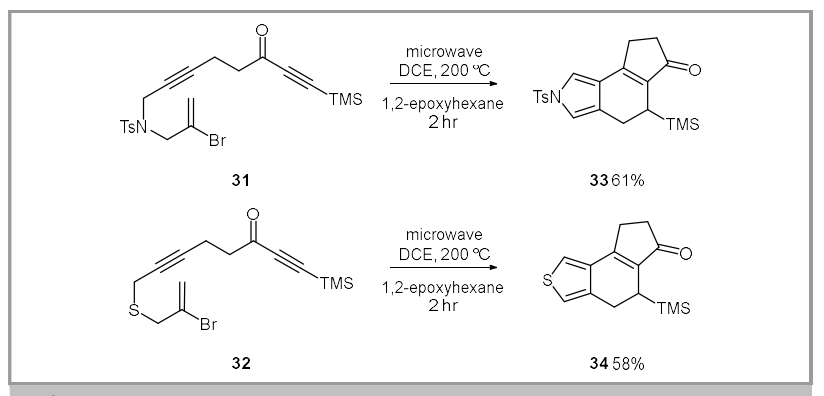

Scheme 10 Microwave synthesis of annulated pyrrole 33 and thiophene 34

Multiple pathways have been proposed to account for this transformation (Scheme 11). ${ }^{9}$ The first step of the mechanistic proposal can be divided into either concerted or stepwise pathways. In the concerted pathway, the labelled precursor 35 proceeds directly in one step via a propargylic ene reaction to the alkenyl allene 36, which can then undergo a Diels-Alder cyclisation to provide the observed product 37. A stepwise mechanism may also account for the formation of alkenyl allene $\mathbf{3 6}$, proceeding via the diradical $\mathbf{3 8}$. The diradical $\mathbf{3 8}$ abstracts a deuteron to give the vicinal diradical 39. Further rearrangement of this intermediate, followed by cyclisation and radical-radical recombination would provide the product 37 . 


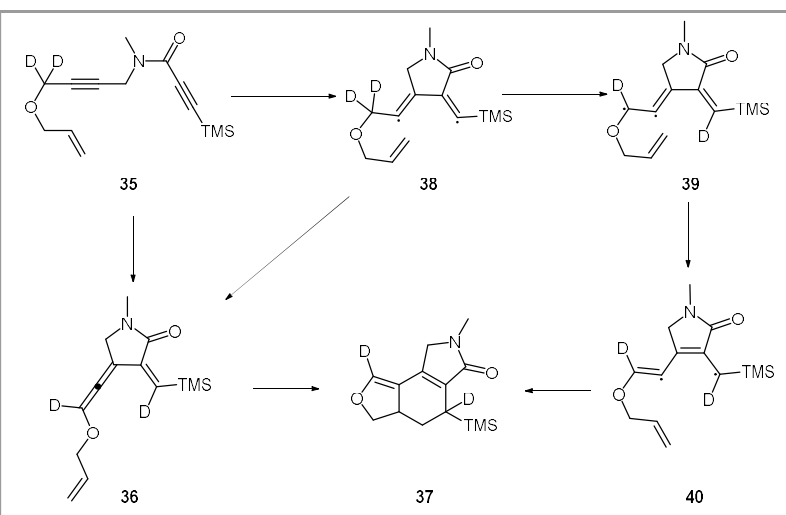

Scheme 11 Proposed mechanism for the observed cyclisation of the deuterium labelled thermolysis precursor 35

The two distinct pathways leading to either $\mathbf{3 6}$ or $\mathbf{3 8}$ were proposed after comparing the mechanism of our transformation to the ene reaction. For a number of decades it has been suggested that the ene reaction exists on the interface between concerted and stepwise mechanisms, with specific examples to support both proposals. ${ }^{16}$ Recent computational experiments on the ene reaction however have provided evidence for a one step asynchronous mechanism, where the carbon-carbon bond formation is more advanced than the hydrogen transfer, for a range of substrates. ${ }^{17}$ Studies on the related Schmittel cyclisation ${ }^{18}$ also provides some insight to the mechanism of our transformation. Early computational studies by Engels suggested that the Schmittel cyclisation may follow either a concerted or stepwise pathway depending on the substrate. ${ }^{19}$ Singleton also showed that the mechanism of the cyclisation was substrate dependent, but his studies pointed to a more complex mechanistic phenomenon. ${ }^{20}$ Instead of dividing the mechanism into concerted and stepwise pathways, Singleton demonstrated that there is a single transition state that leads to either the concerted product or the diradical intermediate, giving rise to a bifurcating reaction pathway. ${ }^{21}$ After early kinetic isotope experimental observations supporting a stepwise mechanism, ${ }^{22}$ Schmittel later supported this concept with his own computational experiments. ${ }^{23}$ We propose that our transformation may exhibit the complex mechanistic behavior seen for both the ene reaction and Schmittel cyclisations, based upon our own previously reported observations. In a previous publication, it was shown that the replacement of the protons with deuterium led to a threefold decrease in the rate of reaction. ${ }^{9}$ Furthermore, the introduction of radical traps did not lead to the expected trapped products. These observations are consistent with the concerted mechanism suggested by other groups working in this area.24,25 As a counterpoint to these observations, the unusual formation of the compound $\mathbf{4 2}$ in a $30 \%$ yield from the ketone $\mathbf{4 1}$, and the isolation of the byproduct $\mathbf{4 4}$ from the cyclisation of $\mathbf{4 5}$ have been attributed to radical mechanisms (Scheme 12). ${ }^{9}$

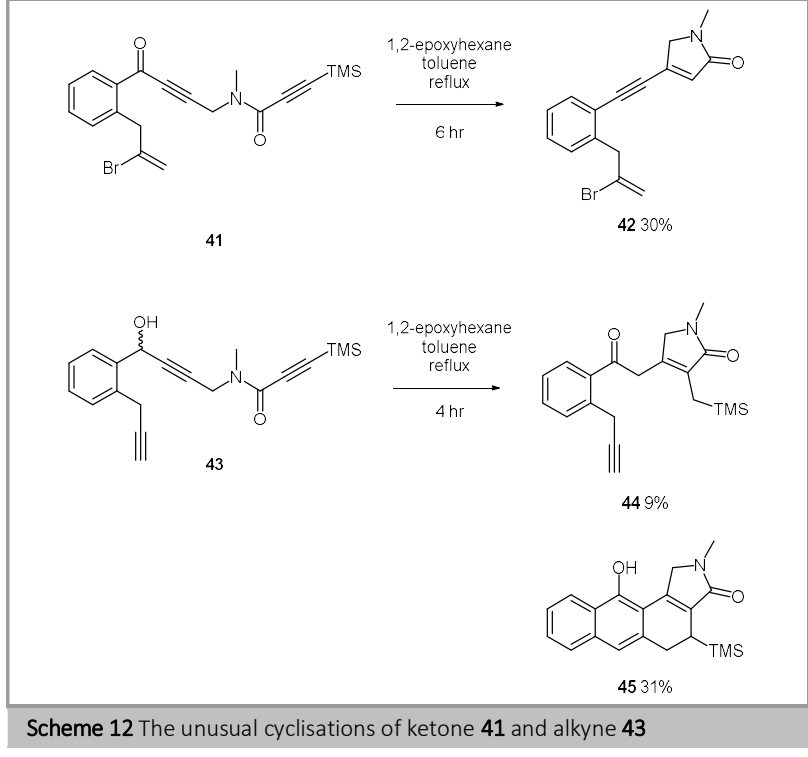

Concurrent with our studies on the synthesis of lactonamycin and related compounds, a palladium assisted cascade cyclisation of substituted furans was also being investigated (Scheme 13). We have previously shown that carbon centered radicals can add to furans to provide substituted cyclopentenes through a fragmentation sequence. For example, the alkenyl bromide $\mathbf{4 8}$ was heated in toluene in the presence of tri-n-butyltin hydride and AIBN to give the bicycle 49 in 51\% yield. ${ }^{26}$ This mechanism involves a radical fragmentation of the furan ring before a $[2+2+2]$ electocyclisation provides the aromatic ring. In later work, we demonstrated that the sulfone $\mathbf{5 0}$ can also undergo a radical mediated cyclisation with concomitant furan fragmentation to afford the tricycle $\mathbf{5 1}$, albeit in a reduced yield of $11 \% .{ }^{27}$

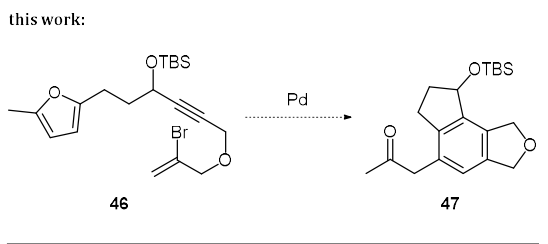

previous work:
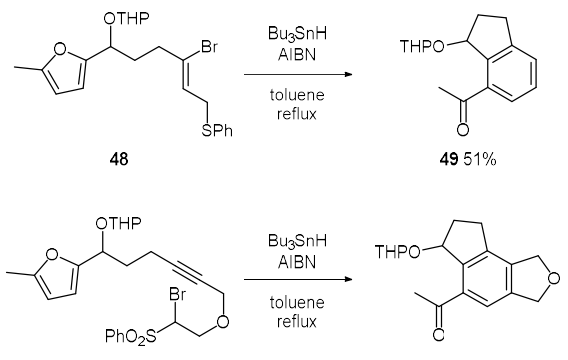

50 $5111 \%$

Scheme 13 The palladium-mediated cascade and previous work on tin mediated cascades 
In an effort to improve the yield of this process, we prepared the ether $\mathbf{4 6}$ for a palladium mediated cyclisation (Scheme 14). The aldehyde $\mathbf{5 3}$ was prepared by an acid catalyzed Michael addition with acrolein. Treatment of the aldehyde with ethynylmagnesium bromide and protection of the resultant alcohol gave the alkyne 54. The propargyl alcohol $\mathbf{5 5}$ was formed and then allylated with 2,3-dibromopropene to furnish the cyclisation precursor $\mathbf{4 6}$ for the palladium studies.

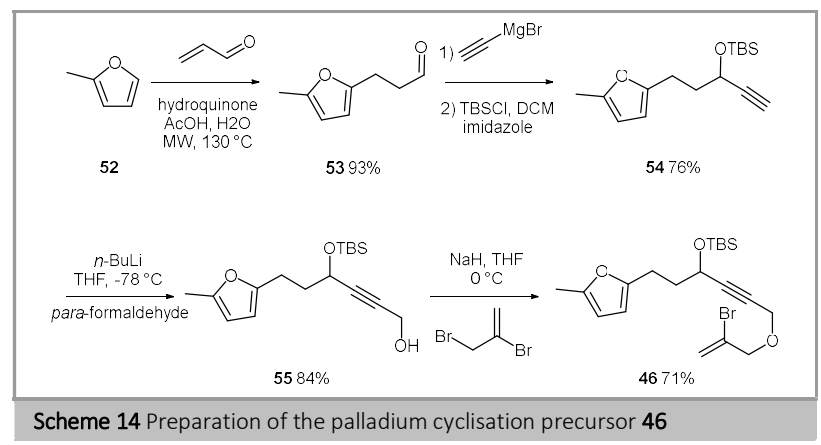

The alkenyl bromide 46 was heated in the presence of palladium (II), providing the tricyclic ketone 47 in $28 \%$ yield (Scheme 15). This finding was remarkable as the precedent for a palladium mediated fragmentation of furan was limited. The only example at the time of this research was completed by Grimaud, who showed that a palladium mediated fragmentation was a convenient means of tandem ring closure and formation $\alpha, \beta$-unsaturated aldehydes. ${ }^{28}$ In contrast to Grimaud's work, which featured a single ring closure, we were able to form three rings in one pot. Further examples of palladium mediated cyclisation and concomitant furan fragmentation have since been disclosed.29 Notably, the yield, 28\%, for the palladium mediated domino reaction was an improvement previously investigated tin radical procedure.

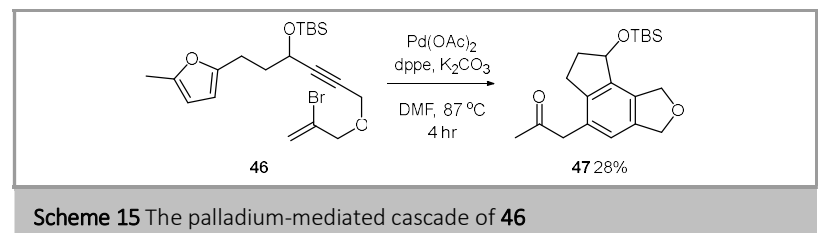

Additional examples were prepared from the alcohol $\mathbf{5 5}$ following the chemistry outlined for the thermal cyclisation precursors $\mathbf{3 1}$ and $\mathbf{3 2}$ disclosed earlier in this publication. With the precursors in hand, the palladium cyclisation fragmentation sequence was completed forming the expected aromatic products 59 and $\mathbf{6 0}$ from the diester 56 and amine 57 respectively (Scheme 16). The sulfide $\mathbf{5 8}$ however unexpectedly yielded the cyclopentadiene derivative $\mathbf{6 1}$ as the sole product. In this case, it is also notable that the sulfide oxidized under reaction conditions to provide the sulfone.

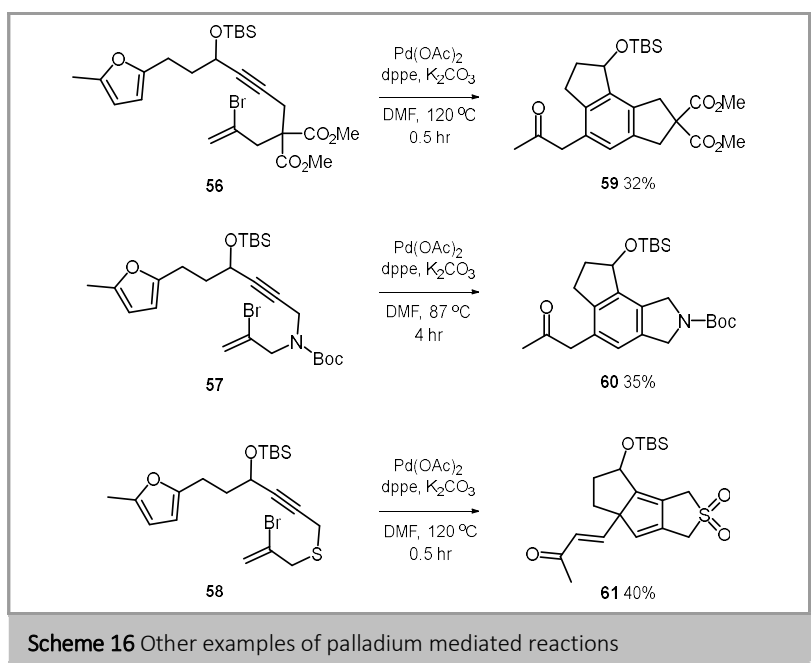

In the case of the ether precursor 46, initial analysis of the reaction mixture showed two major products, but on continued heating under reflux one product diminished and the ketone $\mathbf{4 7}$ was isolated as the sole product. Based on our observations, it is proposed that all examples proceed via a cyclopentadiene intermediate, isolated as the sole product for the sulfide $\mathbf{5 8}$. The cyclopentadiene $\mathbf{6 5}$ will then undergo ring expansion and aromatization to give the bis-annulated products (Scheme 17). In the case of the sulfide, further ring expansion was prevented due to increased ring strain induced by the presence of the sulfone moiety.

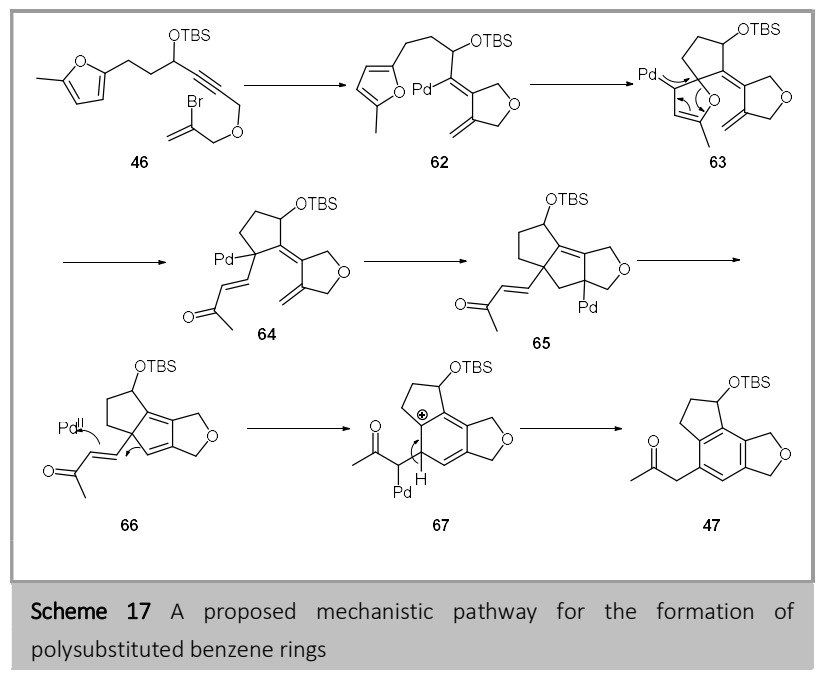

In order to avoid the use of metallic reagents in our cyclisation reactions and to attempt to improve the yields of the cyclized products, we investigated the thermal chemistry of these substrates. Heating the substrate $\mathbf{4 6}$ in the absence of palladium unfortunately yielded only starting material after two hours (Scheme 18). The transformation was also attempted at $200^{\circ} \mathrm{C}$ in a microwave reactor, without success. 


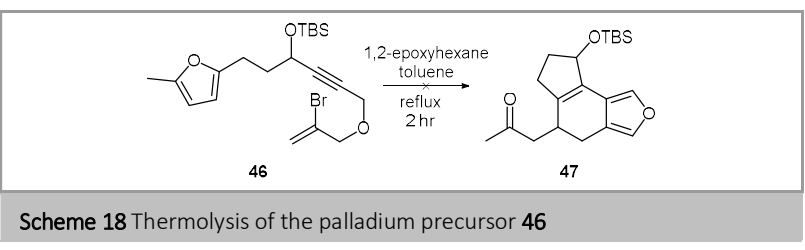

Given our successful use of diyne systems in our approach to lactonamycin (Scheme 3), we decided to replace the bromoalkene with an alkyne to provide the new cyclisation substrate 68 (Scheme 19). This was accomplished in good yield from the previously synthesized propargyl alcohol 55. In this new approach, the furan ring will be acting as the dienophile before the fragmentation sequence to give the tricyclic product 69.

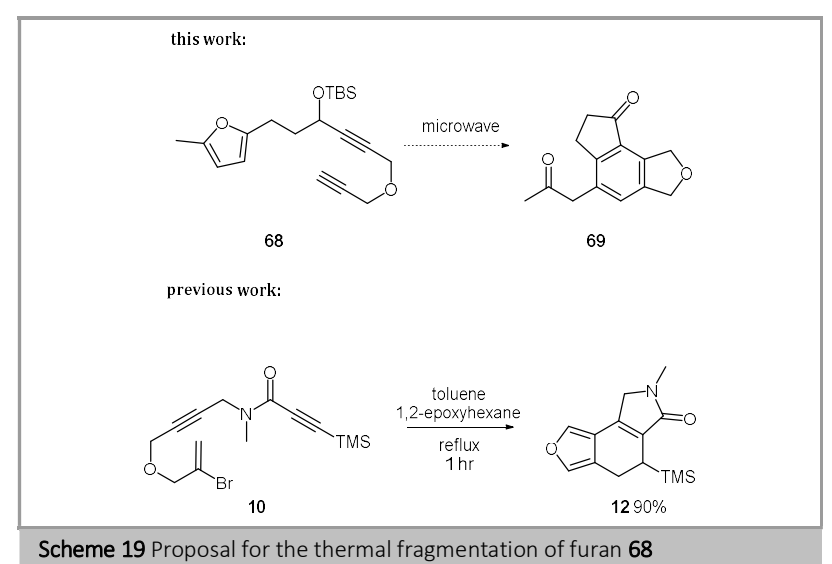

Scheme 19 Proposal for the thermal fragmentation of furan 68

Gratifyingly, when the alkyne $\mathbf{6 8}$ was heated in DMF under microwave irradiation, the pentasubstituted benzene derivative 69 was isolated in $45 \%$ yield (Scheme 20 ). ${ }^{30}$ We proposed that the mechanism for this cyclisation follows the same pathway as for the earlier thermal cyclisations (Scheme 11) to give an alkenyl allene intermediate 70, which then undergoes a DielsAlder cycloaddition with furan. Fragmentation of 71, followed by oxidation, leads to the pentasubstituted benzene core of 69 (Scheme 21).

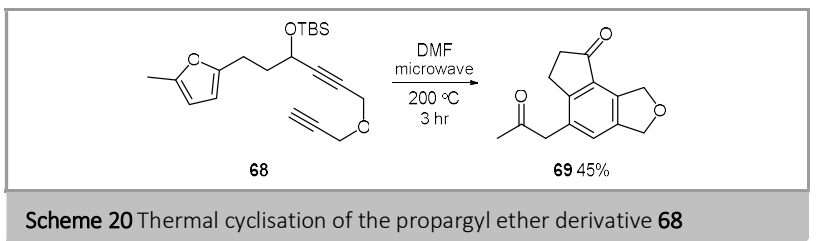

Scheme 20 Thermal cyclisation of the propargyl ether derivative 68

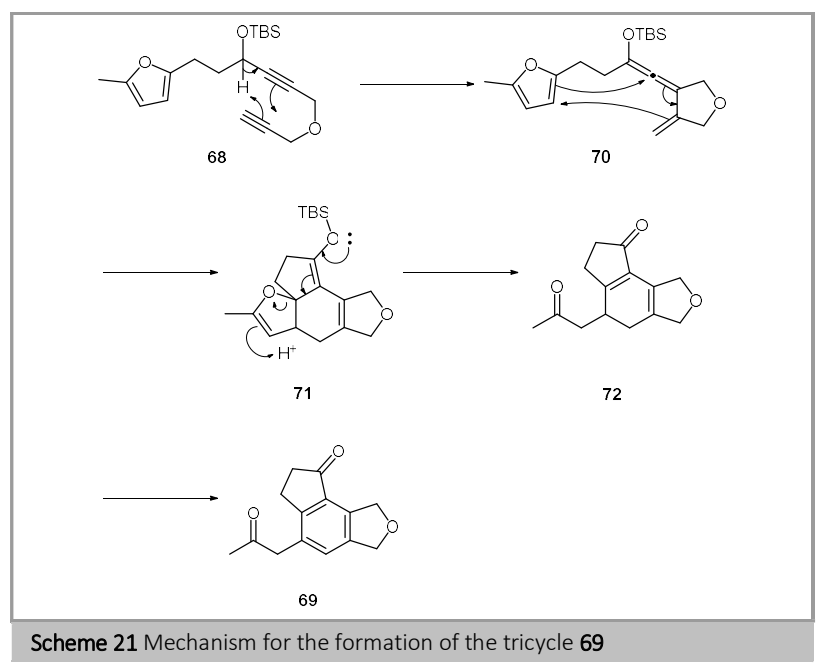

Early investigations on this theme explored the effect of substitution on the furan ring (Scheme 22). It was found that it was possible to prepare the aldehyde $\mathbf{7 6}$ from the mono substituted furan $\mathbf{7 3}$ or the ethyl ketone $\mathbf{7 7}$ from the ethyl substituted furan $\mathbf{7 4}$. The yield for the aldehyde $\mathbf{7 6}$ was notably lower than both the parent compound and ethyl derivative due to the instability of the phenyl acetaldehyde $\mathbf{7 6}$. Unsurprisingly, methyl substitution at the propargylic position, to give the precursor 75, leads to an increased cyclisation yield over the unsubstituted parent compound $\mathbf{6 8 .}$

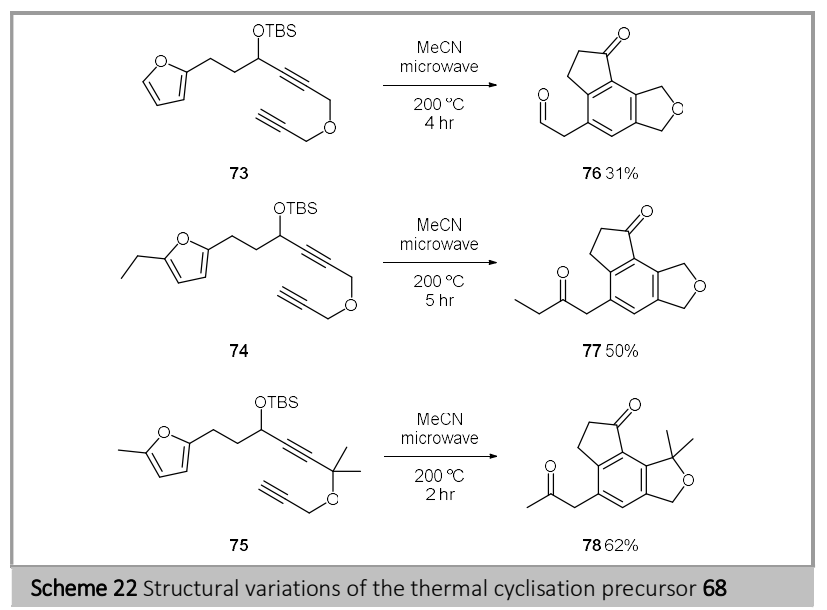

Alcohol 55 (Scheme 14) was coupled with propiolic acid to give the ester 79, which in turn cyclized to give the lactone $\mathbf{8 1}$ in $62 \%$ yield (Scheme 23). Similarly, the carboxylic acid may be formed from the alkyne $\mathbf{5 4}$ (Scheme 14) and esterified with propargyl alcohol to give the isomeric ester 80. Cyclisation of this material under the usual conditions provided the lactone $\mathbf{8 2}$ also in $62 \%$ yield. 


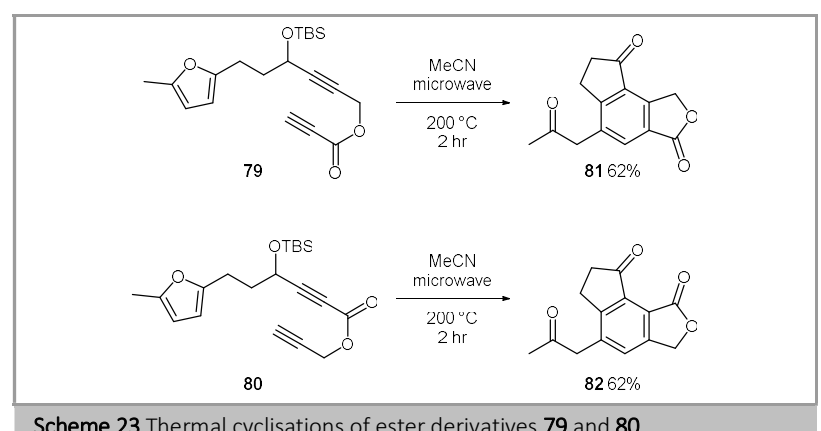

Scheme 23 Thermal cyclisations of ester derivatives 79 and 80

It was proposed that substitution of this side chain would provide hexasubstituted aromatic rings. Methyl substitution was accomplished by the reaction of the alcohol $\mathbf{5 5}$ (Scheme 14) with 1-bromo-2-butyne to give the substrate 83. Under standard conditions, $\mathbf{8 3}$ cyclized to give the hexasubstituted benzene core of $\mathbf{8 6}$ (Scheme 24). Alcohol 56 was also coupled with both phenylpropiolic acid and naphthylpropiolic acid to give 84 and 85 respectively. Cyclisation of these materials provided the lactones $\mathbf{8 7}$ and $\mathbf{8 8}$ with the aromatic rings positioned orthogonally to the tricycle, as shown by x-ray crystallography.

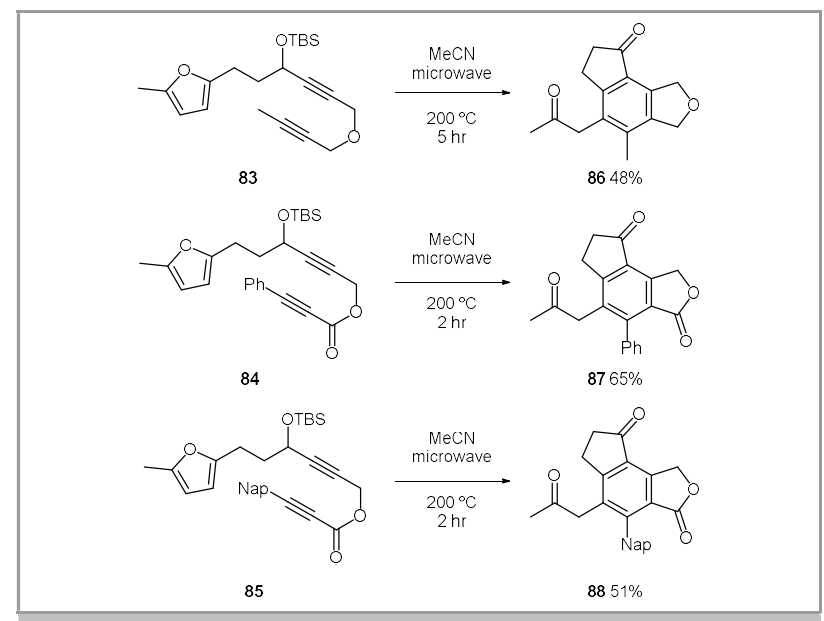

Scheme 24 Variation of the alkyne side chain to form hexasubstituted aromatic rings

In order to compare these results to the palladium methods, the diester $\mathbf{8 9}$, amine $\mathbf{9 0}$, and sulfide $\mathbf{9 1}$ cyclisation precursors were also prepared (Scheme 25). The diester 92 and amine 93 cyclisation substrates formed the expected products in a lower yield than the ether example. The yields were however comparable to the yields for the palladium cyclisation (Scheme 16). In contrast to the palladium methods, the sulfide $\mathbf{9 4}$, featuring a benzene core was accessible using the thermal approach.

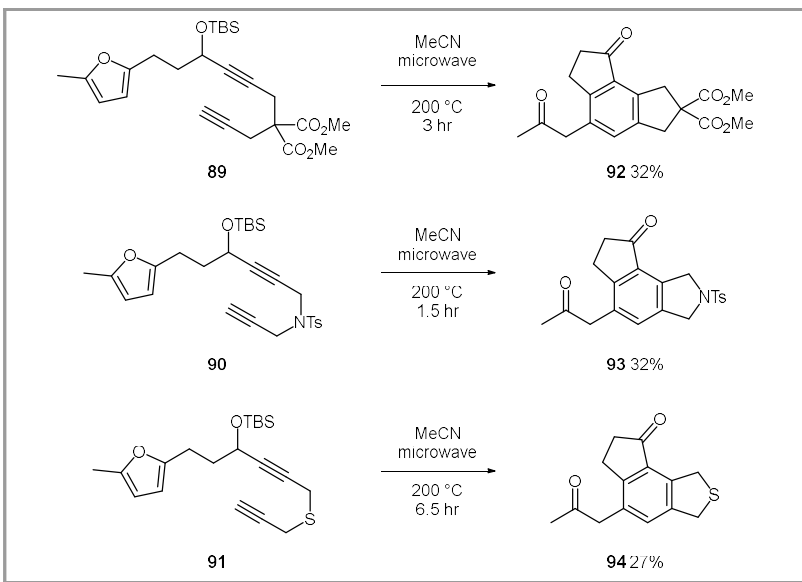

Scheme 25 Cyclisation of diester, nitrogen, and sulfur linked diynes

In addition, we demonstrated that the cyclic ether $\mathbf{1 0 0}$ could also be formed (Scheme 26). The alcohol 96 was deprotonated and reacted with propargyl bromide to give the alkyne 97 . The propargyl alcohol 98 was formed and the ether $\mathbf{9 9}$ synthesized. Cyclisation in acetonitrile furnished the tricycle $\mathbf{1 0 0 .}$

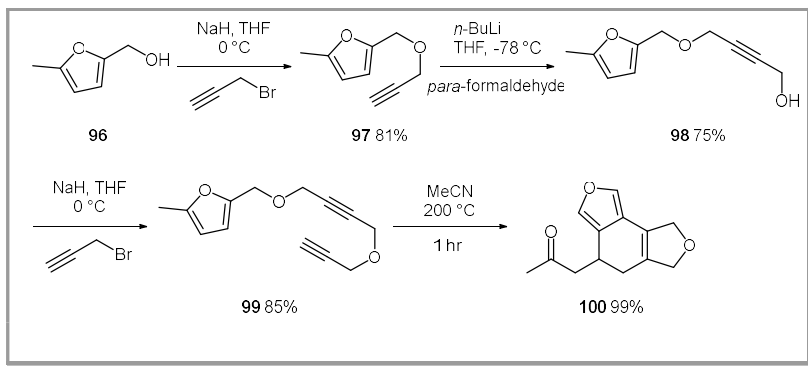

Scheme 26 Cyclisation to form the annulated furan 100 and preparation of the precursor 99

It was proposed that the cyclisation and fragmentation sequence could be performed in an intermolecular fashion using the diyne 102 (Scheme 27). We have previously investigated a similar intermolecular reaction with a number of dienophiles. ${ }^{31}$ In this example, thermolysis of the diyne $\mathbf{1 0 4}$ forms the corresponding alkenyl allene $\mathbf{1 0 5}$ which forms the bicycle upon reaction with allyl alcohol. The adduct is then trapped by the pendant alcohol to provide tricyclic product 106. Danheiser has also reported intra-intermolecular examples. ${ }^{25}$ 


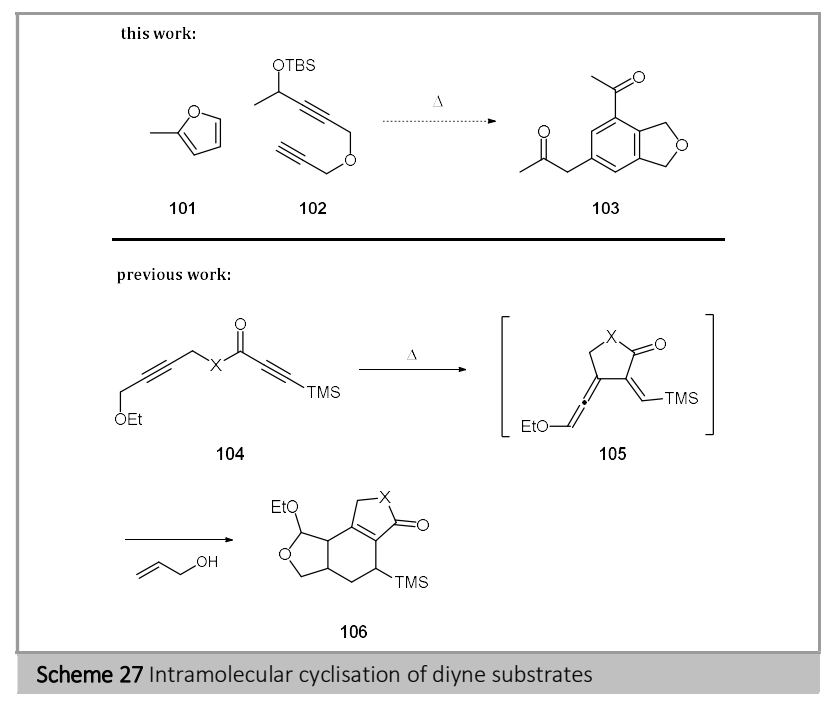

For these studies, the diyne $\mathbf{1 0 2}$ was prepared from butyn-2-ol through a three step sequence (Scheme 28). The alcohol was first protected as the silyl ether $\mathbf{1 0 8}$ before deprotonation and reaction with para-formaldehyde to give the propargyl alcohol 109.32 Treatment of the propargyl alcohol with propargyl bromide in the presence of sodium hydride gave the ether $\mathbf{1 0 2}$.

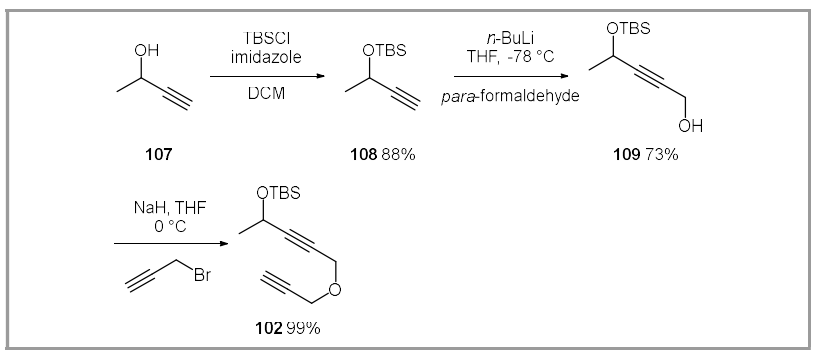

Scheme 28 Preparation of the diyne 102 for the intermolecular cyclisation with furan

Heating the ether $\mathbf{1 0 2}$ in acetonitrile under microwave conditions did not form the intermolecular aromatic product 103 (Scheme 29). Spectral analysis of the crude material however revealed a complex reaction profile that merited further investigation.

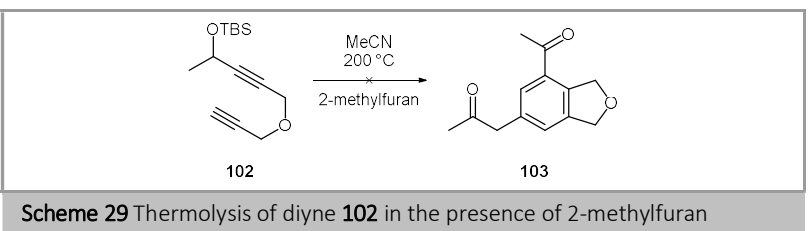

In the absence of the furan component, it was possible to isolate two new products from this reaction. The furan $\mathbf{1 1 0}$ was isolated in a 40\% yield, along with the enone 111 (Scheme 30).

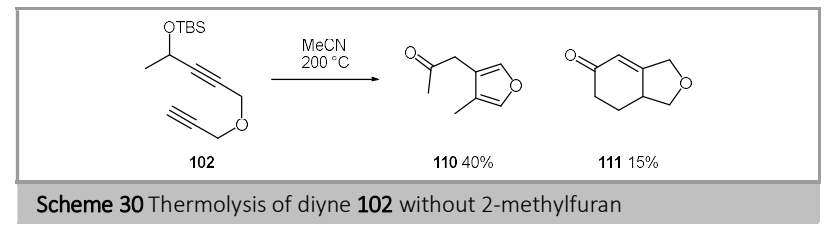

To account for the product distribution, the following mechanism was proposed (Scheme 31). The alkenyl allene 112 is formed following the previously discussed mechanism. Protonation of $\mathbf{1 1 2}$ forms the two regioisomers $\mathbf{1 1 3}$ and $\mathbf{1 1 4}$ The Z-alkene $\mathbf{1 1 3}$ aromatizes and the silyl enol ether $\mathbf{1 1 5}$ is hydrolyzed to give the furan product 110. The cyclic ketone $\mathbf{1 1 1}$ is formed through electocyclisation of the triene 116. The resultant diene $\mathbf{1 1 7}$ is hydrolyzed to form the unsaturated ketone 111.

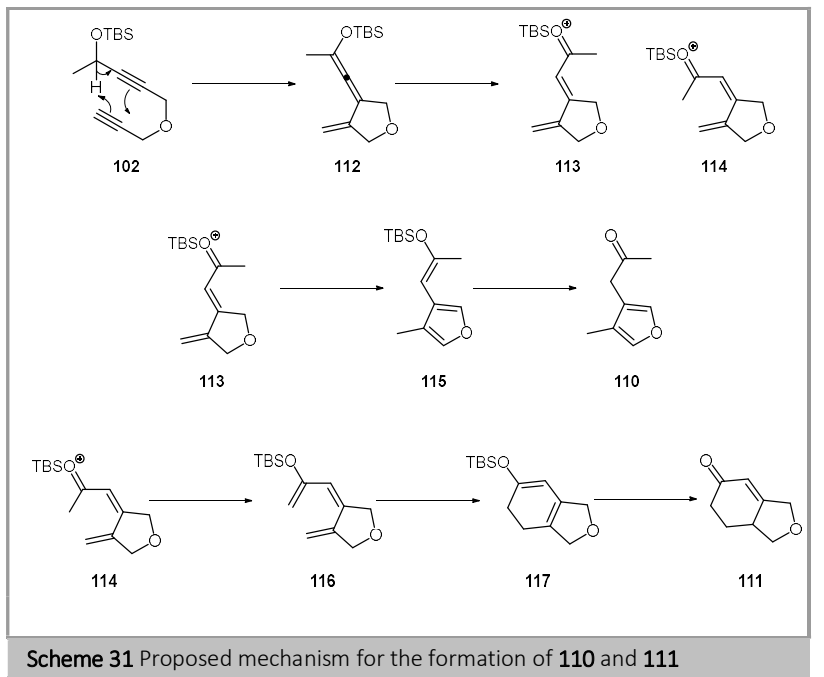

The sulfide 119 was also prepared and this cyclized under identical conditions (Scheme 32). The previously prepared alcohol was converted to thio acetate $\mathbf{1 1 8}$ under Mitsunbou conditions. The thio acetate was cleaved and reacted with propargyl bromide to give the sulfur precursor 119 Thermolysis of the diyne $\mathbf{1 1 9}$ over six hours gave the expected products $\mathbf{1 2 0}$ and $\mathbf{1 2 1}$ in a reduced yield compared to ether variant $\mathbf{1 0 2}$

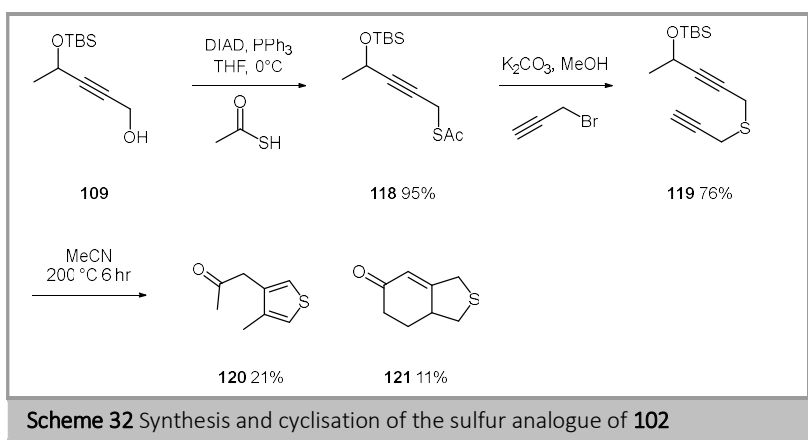

The amine 124 was prepared from the diyne 122 (Scheme 33). Deprotonation and reaction with acetaldehyde, followed by protection of the alcohol, gave the precursor 124. When heated in acetonitrile, a subtly different product profile was observed. The pyrrole 125 and enone 126 were isolated in $41 \%$ and $16 \%$ yield respectively, as well as the previously unobserved tetrasubstituted alkene 127 in 14\% yield. 


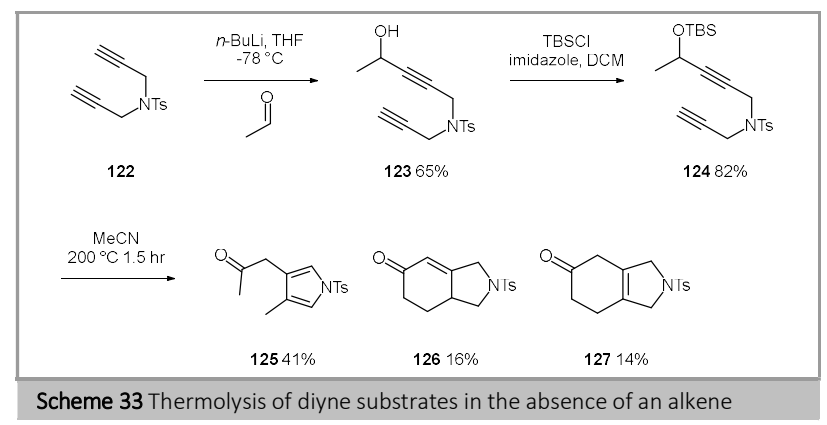

We were also able to apply this chemistry to the synthesis of substituted pyridines by installing a nitrile group in the precursor (Scheme 34). The alcohol $\mathbf{5 6}$ was alkylated to give the nitrile 128; cyclisation of the nitrile provided the pyridine $\mathbf{1 2 9}$ in $42 \%$ yield.

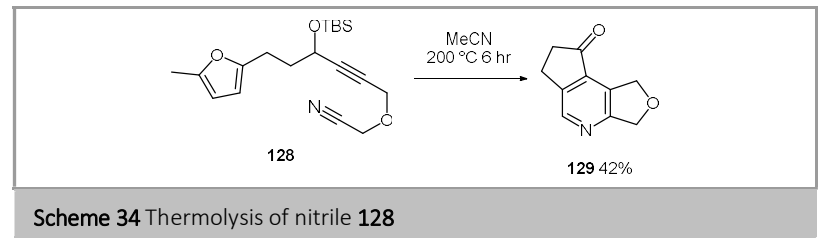

After the initial success in the formation of a pyridine ring, we prepared the cyclisation precursor 130 (Scheme 35). We proposed that the nitrile ester $\mathbf{1 3 0}$ would cyclize to provide the pyridine product 131. However, when 130 was heated in acetonitrile at $200{ }^{\circ} \mathrm{C}$ in the presence of water, the amine $\mathbf{1 3 2}$ was formed unexpectedly in $62 \%$ isolated yield. If the nitrile ester $\mathbf{1 3 0}$ was allowed to stand at room temperature, the DielsAlder product $\mathbf{1 3 3}$ was formed quantitatively. When the adduct 133 was heated for four hours at $200{ }^{\circ} \mathrm{C}$, the amine $\mathbf{1 3 2}$ was formed together with the starting material 130 proceeding via a retro-Diels-Alder reaction.

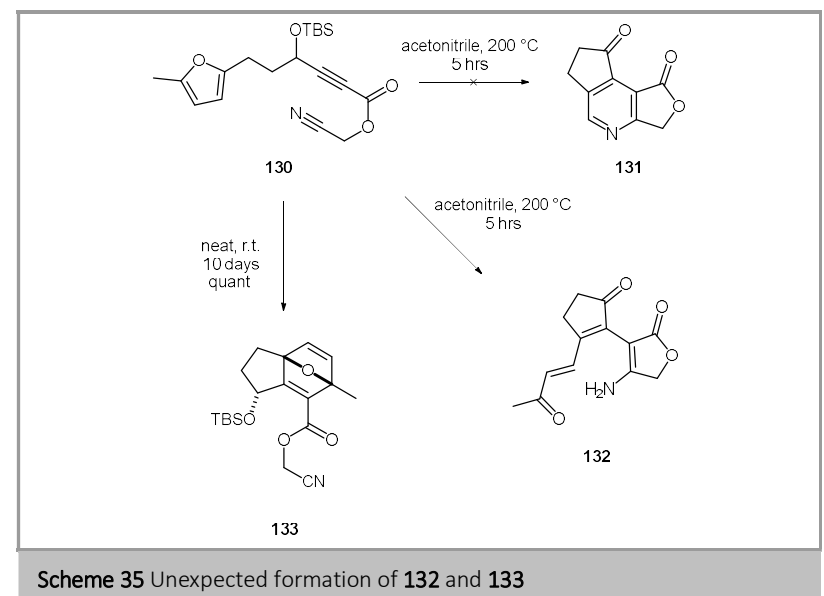

We rationalized the formation of $\mathbf{1 3 2}$ as due to the carbonylcarbonyl steric compression in structure $\mathbf{1 3 1}$ versus the relief of steric compression in 132. The proposed mechanism of this transformation is shown in scheme 36. The furan $\mathbf{1 3 0}$ was presumed to undergo an intramolecular cyano-ene reaction to form the allene 134. ${ }^{25} \mathrm{An}$ intramolecular aza-Diels-Alder then was assumed to furnish the unstable lactone 135. This intermediate then underwent ring opening and cleavage of the carbon nitrogen bond to give the less strained intermediate 132, upon tautomerization. This intriguing reaction is now the subject of further research.

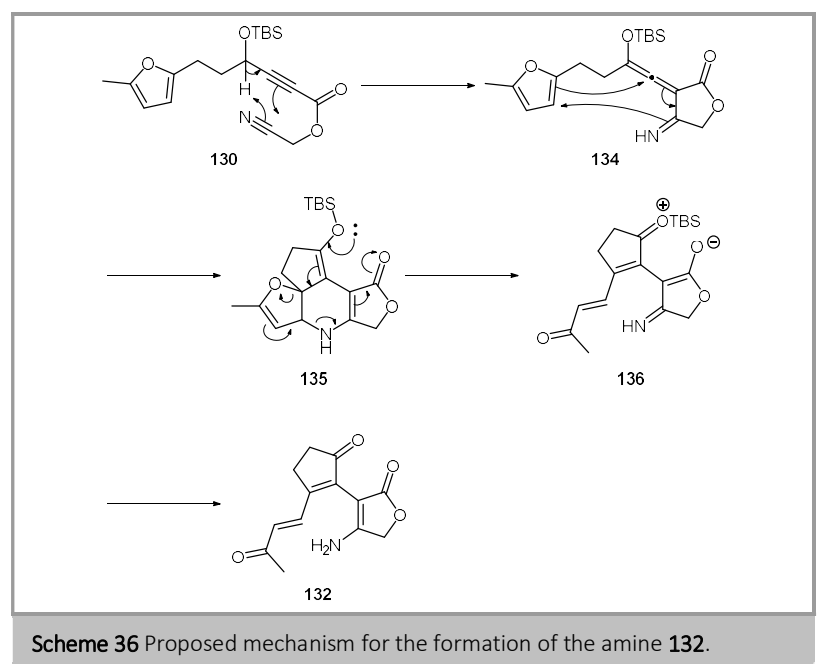

This paper is concerned with our findings on the metal catalyzed versus metal free domino cyclisation reactions of a range of alkene and alkyne containing substrates. We report our extension of existing work on the formation of annulated heteroaromatic compounds, based on earlier work conducted on the synthesis of lactonamycin. We also discuss our findings on the one pot formation of highly substituted benzene rings and the relationship to our investigations on palladium mediated fragmentation of furans.

The experimental section has no title; please leave this line here

Commercially available chemicals and reagents were used as supplied unless otherwise stated. Toluene, DCE, and acetonitrile were distilled from calcium hydride. All solvents for high temperature reactions $(>100$ ${ }^{\circ} \mathrm{C}$ ) were first deoxygenated by sparging for at least 1 hour with nitrogen or argon gas. Reactions were monitored by crude NMR of the RM or by TLC using Merck glass backed TLC plates coated with a $0.25 \mathrm{~mm}$ layer of 60 F254 silica gel. Visualisation was achieved using $254 \mathrm{~nm}$ UV radiation and potassium permanganate, phosphomolybdic acid or vanillin stains as deemed appropriate. Column chromatography was carried out using Merck Kieselgel 60 or Fluorochem (40-63 $\mu \mathrm{m})$. NMR spectroscopy was performed using either Varian NMR System-600 MHz $(600 \mathrm{MHz}$ for $1 \mathrm{H}$ and $151 \mathrm{MHz}$ for 13C), Varian NMR System-500 MHz (500 MHz for $1 \mathrm{H}$ and $126 \mathrm{MHz}$ for $13 \mathrm{C}$ ), or a Bruker AV-400 (400 MHz for $1 \mathrm{H} \mathrm{NMR}$ and $100 \mathrm{MHz}$ for $13 \mathrm{C} \mathrm{NMR}$ ), and referenced relative to the residual nondeuterated solvent peak.. Chemical shifts are reported in parts per million. Spectral peaks are assigned as s (singlet), d (doublet), t (triplet), q (quartet), m (multiplet) and br (broad), and combinations thereof Coupling constants $(\mathrm{J})$ are reported to the nearest $0.5 \mathrm{~Hz}$. Heteronuclear Single Quantum Coherence (HSQC), Heteronuclear Multiple Bond Coherence (HMBC), Correlation Spectroscopy (COSY) and HydrogenDeuterium exchange (H-D) experiments were also run where necessary to allow for the full elucidation of structures. Mass spectrometry was performed using a Fissons Instrument VG Autospec and a Bruker Daltonics Apex III. Infrared spectra were recorded on a Perkin-Elmer 1710 Fourier transform instrument with an ATR attachment. Melting points were recorded using a Gallenkamp melting point apparatus and are uncorrected.

\section{Procedures}

5-(Trimethylsilyl)-7,8-dihydro-4H-indeno[4,5-c]furan-6(5H)-one (19) 
8-(2-Bromoallyloxy)-1-(trimethylsilyl)octa-1,6-diyn-3-one (300 mg, 0.9 mmol) and epoxyhexene in DCE (2 mL) were heated to $185^{\circ} \mathrm{C}$ using a microwave reactor. After 2 hours, the volatiles were removed under vacuum to give a crystalline solid. The crude material was then purified by column chromatography ( $50 \%$ ethyl acetate in hexane) to provide the title compound as a white crystalline solid (180 mg, $0.73 \mathrm{mmol}, 81 \%$ )

$\mathrm{R}_{\mathrm{f}}=0.30$ (25\% ethyl acetate in hexane)

Melting Point: $107.1^{\circ} \mathrm{C}-110.4{ }^{\circ} \mathrm{C}\left(\mathrm{CHCl}_{3}\right)$

IR (neat): 3134, 2948, 1680, 1619, 1435, 1403, 1108, 1025, 831, 813, $755 \mathrm{~cm}^{-1}$.

${ }^{1} \mathrm{H} \mathrm{NMR}\left(\mathrm{CDCl}_{3}, 400 \mathrm{MHz}\right): \delta=7.62-7.49(\mathrm{~m}, 1 \mathrm{H}), 7.19(\mathrm{t}, J=2.0 \mathrm{~Hz}, 1 \mathrm{H})$, 2.91-2.67 (m, 4H), $2.53(\mathrm{t}, J=5.0 \mathrm{~Hz}, 2 \mathrm{H}), 2.34-2.29(\mathrm{~m}, 1 \mathrm{H}),-0.14(\mathrm{~s}$, $9 \mathrm{H})$.

${ }^{13} \mathrm{C} \mathrm{NMR}\left(\mathrm{CDCl}_{3}, 100 \mathrm{MHz}\right): \delta=206.8,156.4,140.3,138.5,137.7,122.4$, $121.4,35.0,25.6,21.8,19.4,-2.2$.

HRMS (ES+): $m / z[\mathrm{M}+\mathrm{H}]^{+}$calcd for $\mathrm{C}_{14} \mathrm{H}_{19} \mathrm{O} 2 \mathrm{Si}$ : 247.1154; found: 247.1165 .

2-Tosyl-5-(trimethylsilyl)-4,5,7,8-tetrahydrocyclopenta[e]isoindol$6(2 \mathrm{H})$-one (33)

( $N$-(2-Bromoallyl)- $N$-(6-oxo-8-(trimethylsilyl)octa-2,7-diynyl)-4methylbenzenesulfonamide (60 $\mathrm{mg}, 0.12 \mathrm{mmol}$ ) and 1,2-epoxyhexane (0.14 mL, $1.2 \mathrm{mmol}$ ) in DCE $(1.2 \mathrm{~mL})$ were heated to $200{ }^{\circ} \mathrm{C}$ for 2 hours using a microwave reactor. The mixture was then concentrated under reduced pressure and the residue purified by column chromatography ( $30 \%$ EtOAc in hexane) to furnish the title compound as a pale yellow gum (29 mg, $0.073 \mathrm{mmol}, 61 \%)$.

$\mathrm{R}_{\mathrm{f}}=0.36$ (30\% ethyl acetate in hexane)

IR (neat) 2953, 2924, 2852, 1685, 1615, 1535, 1370, 1286, 1171, 1054, $841,675 \mathrm{~cm}^{-1}$.

${ }^{1} \mathrm{H} \mathrm{NMR}\left(\mathrm{CDCl}_{3}, 400 \mathrm{MHz}\right): \delta=7.77-7.68(\mathrm{~m}, 2 \mathrm{H}), 7.30-7.26(\mathrm{~m}, 2 \mathrm{H})$, $7.22(\mathrm{~d}, J=2.0 \mathrm{~Hz}, 1 \mathrm{H}), 6.88(\mathrm{dt}, J=2.0,1.0 \mathrm{~Hz}, 1 \mathrm{H}), 2.85-2.62(\mathrm{~m}, 4 \mathrm{H})$, $2.51(\mathrm{t}, J=5.0 \mathrm{~Hz}, 2 \mathrm{H}), 2.39(\mathrm{~s}, 3 \mathrm{H}), 2.30-2.22(\mathrm{~m}, 1 \mathrm{H}),-0.26(\mathrm{~s}, 9 \mathrm{H})$.

${ }^{13} \mathrm{C} \mathrm{NMR}\left(\mathrm{CDCl}_{3}, 100 \mathrm{MHz}\right) ; \delta=206.7,157.3,145.3,140.5,136.0,130.1$, $126.9,126.3,124.9,116.7,116.6,35.0,25.3,21.7,21.6,21.2,-2.3$.

HRMS (ES+): $m / z[\mathrm{M}+\mathrm{H}]^{+}$calcd for $\mathrm{C}_{21} \mathrm{H}_{26} \mathrm{NO}_{3} \mathrm{SSi}$ : 400.1403; found: 400.1400 .

5-(Trimethylsilyl)-7,8-dihydro-4H-indeno[5,4-c]thiophen-6(5H)one (34)

8-(2-Bromoallylthio)-1-(trimethylsilyl)octa-1,6-diyn-3-one (15 $\mathrm{mg}$ $0.043 \mathrm{mmol})$ and 1,2 -epoxyhexane $(0.05 \mathrm{~mL}, 0.4 \mathrm{mmol})$ in DCE $(0.4 \mathrm{~mL})$ were heated to $200{ }^{\circ} \mathrm{C}$ for 2 hours using a microwave reactor. The mixture was then concentrated under reduced pressure and the residue purified by column chromatography (15\% ethyl acetate in hexane) to furnish the title compound as a pale yellow gum $(6.5 \mathrm{mg}, 0.025 \mathrm{mmol}$, $58 \%)$.

$\mathrm{R}_{\mathrm{f}}=0.15$ (15\% ethyl acetate in hexane)

IR (neat) 2958, 2924, 1686, 1603, 1350, 1250, $848 \mathrm{~cm}^{-1}$

${ }^{1} \mathrm{H} \mathrm{NMR}\left(\mathrm{CDCl}_{3}, 500 \mathrm{MHz}\right) \delta=7.35(\mathrm{~d}, J=2.5 \mathrm{~Hz}, 1 \mathrm{H}), 6.93(\mathrm{ddd}, J=2.5,2$, $0.5 \mathrm{~Hz}, 1 \mathrm{H}), 3.08-2.90(\mathrm{~m}, 3 \mathrm{H}), 2.81-2.74(\mathrm{~m}, 1 \mathrm{H}), 2.57(\mathrm{t}, J=5.0 \mathrm{~Hz}$, $2 \mathrm{H}), 2.33(\mathrm{ddt}, J=8.0,2.5,1 \mathrm{~Hz}, 1 \mathrm{H}),-0.17(\mathrm{~s}, 9 \mathrm{H})$.

13C NMR $\left(\mathrm{CDCl}_{3}, 125 \mathrm{MHz}\right) \delta=207.4,159.2,140.3,138.8,136.7,121.6$, $119.4,35.2,26.1,25.3,22.2,-2.3$.

HRMS (ES+): $m / z[\mathrm{M}+\mathrm{H}]^{+}$calcd for $\mathrm{C}_{14} \mathrm{H}_{18} \mathrm{OSSi}$ : 262.0848; found: 262.0846.

\section{1-(8-(tert-Butyldimethylsilyloxy)-3,6,7,8-tetrahydro-1H-} indeno[4,5-c]furan-5-yl)propan-2-one (47)

To a stirred solution of triphenylphosphine (180 mg, $0.68 \mathrm{mmol})$, potassium carbonate (630 $\mathrm{mg}, 4.50 \mathrm{mmol}$ ) and (6-(2-bromoallyloxy)-1(5-methylfuran-2-yl)hex-4-yn-3-yloxy)(tert-butyl)dimethylsilane (1.0 g, $2.3 \mathrm{mmol}$ ) in acetonitrile $(20 \mathrm{~mL})$ was added palladium (II) acetate (50 $\mathrm{mg}, 0.23 \mathrm{mmol})$. The resulting mixture was heated at $80{ }^{\circ} \mathrm{C}$ for 5 hours and quenched with water $(40 \mathrm{~mL})$ and extracted with diethyl ether $(3 \mathrm{x}$ $50 \mathrm{~mL}$ ). The combined organic fractions were then dried over magnesium sulfate, filtered and concentrated under reduced pressure. The crude product was purified by column chromatography $(10 \%$ diethyl ether in hexane) to yield the title compound as a orange/green viscous oil ( $230 \mathrm{mg}, 0.65 \mathrm{mmol}, 28 \%$ ).

IR (neat): 3403, 2928, 2854, 1709, 1412, $1358 \mathrm{~cm}^{-1}$

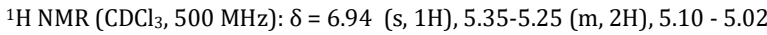
(m, 3H), $3.68(\mathrm{~m}, 2 \mathrm{H}), 2.90$ (ddd, $J=15.5,9,2,1 \mathrm{H}), 2.69-2.61(\mathrm{~m}, 1 \mathrm{H}$ ) 2.52-2.46 (m, 1H), $2.16(\mathrm{~s}, 3 \mathrm{H}), 1.93(\mathrm{dtd}, J=12.5,9,7.5,1 \mathrm{H}), 0.93(\mathrm{~s}$ $9 \mathrm{H}), 0.16(\mathrm{~d}, J=10.5,6 \mathrm{H})$.

${ }^{13} \mathrm{C} \mathrm{NMR}\left(\mathrm{CDCl}_{3}, 126 \mathrm{MHz}\right): \delta=205.7,140.8,139.0,134.6,129.6,121.4$, $76.4,72.9,72.4,48.4,36.4,29.3,28.5,25.8,18.0,-4.2,-4.8$.

HRMS (ESI+): $m / z$ [M+Na] ${ }^{+}$calcd for $\mathrm{C}_{20} \mathrm{H}_{30} \mathrm{O}_{3} \mathrm{SiNa}$ : 369.1862; found: 369.1860 .

Dimethyl 8-(tert-butyldimethylsilyloxy)-5-(2-oxopropyl)-3,6,7,8tetrahydroas-indacene-2,2(1H)-dicarboxylate (59)

Dimethyl 2-(2-bromoallyl)-2-(4-(tert-butyldimethylsilyloxy)-6-(5methylfuran-2-yl)hex-2-ynyl)malonate ( $400 \mathrm{mg}, 0.74 \mathrm{mmol})$, DPPE (60 $\mathrm{mg}, 0.15 \mathrm{mmol}$ ), palladium (II) acetate $(17 \mathrm{mg}, 0.074 \mathrm{mmol})$, potassium carbonate (200 mg, $1.5 \mathrm{mmol}$ ) was heated to $120^{\circ} \mathrm{C}$ in DMF (50 mL) for 25 minutes. The reaction mixture was then diluted with water $(500 \mathrm{~mL})$ and extracted with diethyl ether ( $3 \times 250 \mathrm{~mL})$, dried over magnesium sulfate, filtered and concentrated under reduced pressure. The crude product was purified by column chromatography $(40 \%$ diethyl ether in hexane) to yield the title compound as a colourless oil (110 mg, 0.24 mmol, 32\%).

IR (neat) 2954, 2856, 1734, $1472 \mathrm{~cm}^{-1}$

${ }^{1} \mathrm{H} \mathrm{NMR}\left(\mathrm{CDCl}_{3}, 500 \mathrm{MHz}\right): \delta=6.92(\mathrm{~s}, 1 \mathrm{H}), 5.34(\mathrm{t}, J=6.5 \mathrm{~Hz}, 1 \mathrm{H}), 3.76$ (m, 7H), 3.67-3.45 (m, 5H), 2.88 (ddd, $J=15.5,9.0,3.0 \mathrm{~Hz}, 1 \mathrm{H}), 2.60(\mathrm{dt}, J$ $=16,8,1 \mathrm{H}), 2.48-2.39(\mathrm{~m}, 1 \mathrm{H}), 2.14(\mathrm{~s}, 3 \mathrm{H}), 1.93(\mathrm{dtd}, J=13.0,8.5,6.5$ $\mathrm{Hz}, 1 \mathrm{H}), 0.94$ (s, 9H), $0.18(\mathrm{~d}, J=22,6 \mathrm{H})$

${ }^{13} \mathrm{C} \mathrm{NMR}\left(\mathrm{CDCl}_{3}, 126 \mathrm{MHz}\right): \delta=206.1,172.4,172.1,141.0,140.9,139.7$, 135.6, 129.2, 124.8, 76.3, 60.5, 52.9, 52.8, 48.6, 40.1, 38.8, 36.1, 29.3 $25.9,18.0,-4.1,-4.7$.

HRMS (ESI+): $m / z[\mathrm{M}+\mathrm{Na}]^{+}$calcd for $\mathrm{C}_{25} \mathrm{H}_{36} \mathrm{NaO}_{6} \mathrm{Si}$ : 483.2179; found: 483.2200.

tert-Butyl $\quad 8$-(tert-butyldimethylsilyloxy)-5-(2-oxopropyl)-3,6,7,8tetrahydrocyclopenta[e]isoindole-2(1H)-carboxylate $(60)$

To a stirring solution of tert-butyl 2-bromoallyl(4-(tertbutyldimethylsilyloxy)-6-(5-methylfuran-2-yl)hex-2-ynyl)carbamate (500 $\mathrm{mg}, 0.95 \mathrm{mmol}$ ), dppe (75 $\mathrm{mg}, 0.19 \mathrm{mmol}$ ), potassium carbonate (260 $\mathrm{mg}, 1.9 \mathrm{mmol}$ ) in DMF (25 mL) was added palladium (II) acetate ( $22 \mathrm{mg}, 0.095 \mathrm{mmol}$ ) in one lot. The reaction mixture was heated to 87 ${ }^{\circ} \mathrm{C}$ for 4 hours and diluted with water $(250 \mathrm{~mL})$ whereupon it was then extracted with diethyl ether $(3 \times 100 \mathrm{~mL})$. The combined organic layers were dried over magnesium sulfate, filtered and concentrated under reduced pressure. The crude product was purified by column chromatography (20\% diethyl ether in hexane) to yield the title compound as a white solid (150 mg, $0.34 \mathrm{mmol}, 35 \%$ ).

MP: $112-115^{\circ} \mathrm{C}$

IR (neat): 2929, 2857, 1697, 1472, $1399 \mathrm{~cm}^{-1}$

${ }^{1} \mathrm{H} \mathrm{NMR}\left(\mathrm{CDCl}_{3}, 500 \mathrm{MHz}\right): \delta=6.95(\mathrm{~d}, J=24.5 \mathrm{~Hz}, 1 \mathrm{H}), 5.34(\mathrm{t}, J=7.5 \mathrm{~Hz}$, $1 \mathrm{H}), 4.84(\mathrm{dd}, J=23.0,15.0 \mathrm{~Hz}, 1 \mathrm{H}), 4.69-4.99(\mathrm{~m}, 3 \mathrm{H}) 3.67(\mathrm{~d}, J=2.5 \mathrm{~Hz}$ $2 \mathrm{H}), 2.96-2.82(\mathrm{~m}, 1 \mathrm{H}), 2.69-2.58(\mathrm{~m}, 1 \mathrm{H}), 2.55-2.43(\mathrm{~m}, 1 \mathrm{H}), 2.16(\mathrm{~s}, 3 \mathrm{H})$, $1.93(\mathrm{ddt}, J=17.5,12.5,9.0 \mathrm{~Hz}, 1 \mathrm{H}), 1.52$ (d, $J=3.0 \mathrm{~Hz}, 9 \mathrm{H}), 0.95$ (d, $J=$ $9.5 \mathrm{~Hz}, 9 \mathrm{H}), 0.18(\mathrm{~d}, J=21.5 \mathrm{~Hz}, 6 \mathrm{H})$.

${ }^{13} \mathrm{C}-\mathrm{NMR}\left(\mathrm{CDCl}_{3}, 126 \mathrm{MHz}\right): \delta=205.6,154.6,140.7,140.0,136.7,132.9$, $129.8,123.2,79.5,76.6,51.3,51.3,48.4,36.4,29.3,28.6,28.5,28.4,25.9$, $25.9,18.0,-4.1,-5.0$.

HRMS (ESI+): $m / z[\mathrm{M}+\mathrm{Na}]^{+}$calcd for $\mathrm{C}_{25} \mathrm{H}_{39} \mathrm{NNaO}_{4} \mathrm{Si}$ : 468.2546; found: 468.2541 . 
(E)-4-(4-(tert-Butyldimethylsilyloxy)-1,3,4,5,6,6ahexahydropentaleno[1,2-c]thiophen-6a-yl-1,1-dioxide)but-3-en-2one (61)

To a solution of (6-(2-bromoallylthio)-1-(5-methylfuran-2-yl)hex-4-yn3-yloxy)(tert-butyl)dimethylsilane (1.0 g, $2.3 \mathrm{mmol})$, dppe (180 mg, 0.45 $\mathrm{mmol})$, potassium carbonate $(620 \mathrm{mg}, 4.5 \mathrm{mmol})$ in DMF $(40 \mathrm{~mL})$ was added palladium (II) acetate $(50 \mathrm{mg}, 0.23 \mathrm{mmol})$. The reaction mixture was heated to $120{ }^{\circ} \mathrm{C}$ for 30 minutes and then diluted down with water $(400 \mathrm{~mL})$. The mixture was then extracted with diethyl ether $(3 \times 200$ $\mathrm{mL}$ ), dried over magnesium sulfate, filtered and concentrated under reduced pressure. The crude product was then purified by column chromatography $(0-50 \%$ diethyl ether in hexane) to give the title compound as a bright yellow viscous oil ( $360 \mathrm{mg}, 0.90 \mathrm{mmol}, 40 \%$ ).

IR (neat): 3405, 2927, 2855, 1666, 1590, 1462, $1252 \mathrm{~cm}^{-1}$

${ }^{1} \mathrm{H} \mathrm{NMR}\left(\mathrm{CDCl}_{3}, 500 \mathrm{MHz}\right): \delta=7.23(\mathrm{~d}, J=16.0 \mathrm{~Hz}, 1 \mathrm{H}), 6.51(\mathrm{~s}, 1 \mathrm{H}), 6.10$ $(\mathrm{d}, J=16.0 \mathrm{~Hz}, 1 \mathrm{H}), 4.97(\mathrm{dd}, J=4.5,2.5 \mathrm{~Hz}, 1 \mathrm{H}), 4.96-4.92(\mathrm{~m}, 1 \mathrm{H}), 4.76$ $(\mathrm{t}, J=3 \mathrm{~Hz}, 1 \mathrm{H}), 4.10(\mathrm{t}, J=3.0 \mathrm{~Hz}, 2 \mathrm{H}), 2.74-2.65(\mathrm{~m}, 1 \mathrm{H}), 2.45-2.37(\mathrm{~m}$, $1 \mathrm{H}), 2.37-2.29(\mathrm{~m}, 1 \mathrm{H}), 2.27(\mathrm{~s}, 3 \mathrm{H}), 1.85-177(\mathrm{~m}, 1 \mathrm{H}), 0.87(\mathrm{~s}, 9 \mathrm{H}), 0.03$ (d, 6H).

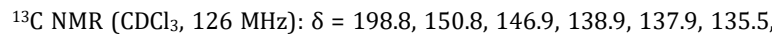
$131.3,129.3,105.7,79.1,37.2,33.0,29.4,27.1,25.8,18.1,-4.8,-4.8$.

HRMS (ESI+): $m / z$ [M+Na] ${ }^{+}$calcd for $\mathrm{C}_{20} \mathrm{H}_{30} \mathrm{NaO}_{4} \mathrm{SSi}$ : 417.1532; found: 417.1548.

\section{5-(2-0xopropyl)-6,7-dihydro-1H-indeno[4,5-c]furan-8(3H)-one (69)}

tert-Butyldimethyl(1-(5-methylfuran-2-yl)-6-(prop-2-ynyloxy)hex-4-yn3 -yloxy)silane ( $50 \mathrm{mg}, 0.14 \mathrm{mmol}$ ) was dissolved in dimethylformamide $\left(5.0 \mathrm{~mL}\right.$ ) and heated to $200{ }^{\circ} \mathrm{C}$ for 3 hours in a microwave. The reaction mixture was decanted into water, stirred for 10 minutes, and the organics extracted with diethyl ether. The organic layer was then washed with brine, dried with magnesium sulfate and concentrated to give the title compound as a white to pale yellow solid (15 mg, 0.065 , $47 \%$ ).

$\mathrm{Rf}=0.20$ (50\% ethyl acetate in petroleum ether).

IR (neat): 2923, 1708, 1463, $1108 \mathrm{~cm}^{-1}$

${ }^{1} \mathrm{H} \mathrm{NMR}\left(\mathrm{CDCl}_{3}, 400 \mathrm{MHz}\right) \delta=7.26(\mathrm{~s}, 1 \mathrm{H}), 5.37(\mathrm{~s}, 2 \mathrm{H}), 5.10(\mathrm{~s}, 2 \mathrm{H}), 3.83$ $(\mathrm{s}, 2 \mathrm{H}), 3.03(\mathrm{t}, J=5.5 \mathrm{~Hz}, 2 \mathrm{H}), 2.70(\mathrm{t}, J=6.0 \mathrm{~Hz}, 2 \mathrm{H}), 2.27(\mathrm{~s}, 3 \mathrm{H})$.

${ }^{13} \mathrm{C} \mathrm{NMR}\left(\mathrm{CDCl}_{3}, 125 \mathrm{MHz}\right) \delta=206.8,204.9,153.8,140.1,136.5,131.9$ $131.7,128.1,73.0,72.6,47.3,36.3,29.9,25.3$

HRMS (EI+): m/z [M]+ calcd for $\mathrm{C}_{14} \mathrm{H}_{14} \mathrm{O}_{3}: 230.0943$; found: 230.0943 .

2-(8-0xo-3,6,7,8-tetrahydro-1 $H$-indeno[4,5-c]furan-5yl)acetaldehyde (76)

tert-Butyl(1-(furan-2-yl)-6-(prop-2-ynyloxy)hex-4-yn-3yloxy)dimethylsilane (50 mg, $0.15 \mathrm{mmol}$ ) was dissolved in DMF (5 mL) in a microwave vial, and purged with nitrogen. The vial was then heated at $200{ }^{\circ} \mathrm{C}$ for 4 hours in the microwave. The reaction mixture was then diluted into water $(20 \mathrm{~mL})$, extracted with diethyl ether, the organic layer washed with brine and then dried with magnesium sulfate. The solvent was removed and the crude purified using column chromatography $(0-50 \%$ ethyl acetate in petroleum ether) to yield a highly viscous yellow oil (10 mg, $0.046 \mathrm{mmol}, 31 \%$ ).

$\mathrm{Rf}=0.25$ (40\% ethyl acetate in petroleum ether)

IR (neat): 2925, 1698, 1588, $1077 \mathrm{~cm}^{-1}$.

1H NMR $\left(\mathrm{CDCl}_{3}, 400 \mathrm{MHz}\right): \delta=9.82(\mathrm{t}, J=1.5 \mathrm{~Hz}, 1 \mathrm{H}), 7.31(\mathrm{~s}, 1 \mathrm{H}), 5.38$ $(\mathrm{t}, J=2.5 \mathrm{~Hz}, 2 \mathrm{H}), 5.10(\mathrm{~s}, 2 \mathrm{H}), 3.85(\mathrm{~d}, J=1.5 \mathrm{~Hz}, 2 \mathrm{H}), 3.05(\mathrm{~m}, 2 \mathrm{H}), 2.72$ $(\mathrm{m}, 2 \mathrm{H})$.

13C NMR ( $\left.\mathrm{CDCl}_{3}, 125 \mathrm{MHz}\right): \delta=206.6,197.7,153.9,140.3,136.9,132.1$, $129.4,128.2,73.0,72.6,47.3,36.3,25.3$.

HRMS (EI-): m/z [M-H] - calcd for $\mathrm{C}_{13} \mathrm{H}_{11} \mathrm{O}_{3}: 215.0708$; found: 215.0692 .

5-(2-0xobutyl)-6,7-dihydro-1H-indeno[4,5-c]furan-8(3H)-one (77)

A microwave vial was charged with tert-butyldimethyl(1-(5-ethylfuran2-yl)-6-(prop-2-ynyloxy)hex-4-yn-3-yloxy)silane (32 mg, $0.09 \mathrm{mmol}$ ) and acetonitrile $(4.9 \mathrm{~mL})$. A single drop of water was then added. The vial was placed in a microwave reactor for 5 hours at $200{ }^{\circ} \mathrm{C}$. The resultant solution was concentrated under reduced pressure and the crude material was then purified via column chromatography (50\% ethyl acetate in pentane) to afford the title compound as an off whitesolid (14 mg, $0.06 \mathrm{mmol}, 63 \%$ ).

Rf: 0.57 (50\% ethyl acetate in pentane)

IR (neat): 2935, 2857, 2361, 1703, 1624, 1592, 1108, $1041 \mathrm{~cm}^{-1}$

${ }^{1} \mathrm{H}$ NMR $\left(\mathrm{CD}_{2} \mathrm{Cl}_{2}, 400 \mathrm{MHz}\right): \delta=7.28(\mathrm{~s}, 1 \mathrm{H}), 5.30(\mathrm{t}, J=2.5 \mathrm{~Hz}, 2 \mathrm{H}), 5.07$ $(\mathrm{m}, 2 \mathrm{H}), 3.82(\mathrm{~s}, 2 \mathrm{H}), 3.02(\mathrm{~m}, 2 \mathrm{H}), 2.66(\mathrm{~m}, 2 \mathrm{H}), 2.56(\mathrm{q}, J=7 \mathrm{~Hz}, 2 \mathrm{H})$, $1.07(\mathrm{t}, J=7 \mathrm{~Hz}, 3 \mathrm{H})$.

${ }^{13} \mathrm{C}$ NMR $\left(\mathrm{CD}_{2} \mathrm{Cl}_{2}, 125 \mathrm{MHz}\right): \delta=207.4,206.4,153.7,139.8,135.9,132.2$ 131.6, 127.8, 72.6, 72.3, 45.6, 36.1, 25.1, 7.6

HRMS No mass found by EI or CI

1,1-Dimethyl-5-(2-oxopropyl)-1H,3H,6H,7H,8H-indeno[4,5-c]furan8-one (78)

A microwave vial charged with tert-butyldimethyl $\{[6-m e t h y l-1-(5-$ methylfuran-2-yl)-6-(prop-2-yn-1-yloxy)hept-4- yn-3-yl]oxy\} silane (50 $\mathrm{mg}, 0.13 \mathrm{mmol})$, acetonitrile $(4.9 \mathrm{~mL})$ and water $(0.05 \mathrm{~mL})$ was heated to $200{ }^{\circ} \mathrm{C}$ for 2 hours under microwave conditions. The solution was concentrated under reduced pressure, and the crude material was purified by column chromatography $(0-60 \%$ ethyl acetate in petroleum ether) to give the title compound as a colourless oil $(21 \mathrm{mg}, 0.081 \mathrm{mmol}$, $61 \%)$.

$\mathrm{Rf}=0.25$ (50\% ethyl acetate in petroleum ether).

IR (neat): 2927, 1703, 1588, 1357, 1277, 1155, $1103 \mathrm{~cm}^{-1}$.

${ }^{1} \mathrm{H} \mathrm{NMR}\left(\mathrm{CDCl}_{3}, 400 \mathrm{MHz}\right): \delta=7.20(\mathrm{~s}, 1 \mathrm{H}), 5.10(\mathrm{~s}, 2 \mathrm{H}), 3.80(\mathrm{~s}, 2 \mathrm{H}), 2.99$ $(\mathrm{m}, 2 \mathrm{H}), 2.69(\mathrm{~m}, 2 \mathrm{H}), 2.26(\mathrm{~s}, 1 \mathrm{H}), 1.67(\mathrm{~s}, 6 \mathrm{H})$.

${ }^{13} \mathrm{C} \mathrm{NMR}\left(\mathrm{CDCl}_{3}, 100 \mathrm{MHz}\right): \delta=206.1,204.9,155.0,144.5,139.7,131.8$, $131.2,128.3,87.7,70.9,47.3,36.7,30.0,26.8,25.0$

HRMS (EI+): $m / z$ [M+H] $]^{+}$calcd for $\mathrm{C}_{16} \mathrm{H}_{19} \mathrm{O}_{3}: 259.1334$; found: 259.1334

5-(2-0xopropyl)-1H,3H,6H,7H,8H-indeno[4,5-c]furan-3,8-dione (81)

A microwave vial charged with 4-[(tert-butyldimethylsilyl)oxy]-6-(5methylfuran-2-yl)hex-2-yn-1-yl prop-2-ynoate $(50 \mathrm{mg}, 0.14 \mathrm{mmol}$ ), acetonitrile $(4.9 \mathrm{~mL})$ and water $(0.05 \mathrm{~mL})$ was heated to $200{ }^{\circ} \mathrm{C}$ for 2 hours under microwave conditions. The solution was concentrated under reduced pressure, and the crude material was purified by column chromatography ( 0 to $50 \%$ ethyl acetate in DCM) to give the title compound as an off-white crystalline solid (21 mg, $0.086 \mathrm{mmol}, 62 \%$ ).

$\mathrm{Rf}=0.35$ (50\% ethyl acetate in DCM)

IR (neat): 2928, 1763, 1709, 1600, 1335, 1166, 1104, $1013 \mathrm{~cm}^{-1}$.

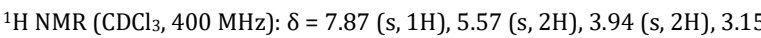
$(\mathrm{m}, 2 \mathrm{H}), 2.79(\mathrm{~m}, 1 \mathrm{H}), 2.32(\mathrm{~s}, 1 \mathrm{H})$.

${ }^{13} \mathrm{C} \mathrm{NMR}\left(\mathrm{CDCl}_{3}, 100 \mathrm{MHz}\right): \delta=205.4,203.7,170.0,161.2,143.6,134.4$, $132.6,131.8,126.3,69.8,47.1,36.3,30.1,26.3$.

HRMS No mass found by EI or CI;

5-(2-0xopropyl)-1H,3H,6H,7H,8H-indeno[4,5-c]furan-1,8-dione (82)

A microwave vial was charged with prop-2-yn-1-yl 4-[(tertbutyldimethylsilyl)oxy]-6-(5-methylfuran-2-yl)hex-2- ynoate $(50 \mathrm{mg}$ $0.11 \mathrm{mmol})$ and acetonitrile $(4.9 \mathrm{~mL})$ and water $(0.05 \mathrm{~mL})$ and was heated to $200{ }^{\circ} \mathrm{C}$ for 2 hours under microwave conditions. The solution was concentrated under reduced pressure yielding the crude material. The crude material was purified by flash column chromatography $(0-2 \%$ methanol in DCM) to give the title compound as a yellow solid (21 mg, $0.086 \mathrm{mmol}, 62 \%$ )

$\mathrm{Rf}=0.28(3 \% \mathrm{MeOH}$ in DCM $)$.

IR (neat): 2926, 1759, 1708, 1289, 1166, 1111, $1017 \mathrm{~cm}^{-1}$.

${ }^{1} \mathrm{H} \mathrm{NMR}\left(\mathrm{CDCl}_{3}, 400 \mathrm{MHz}\right): \delta=7.50(\mathrm{~s}, 1 \mathrm{H}), 5.32(\mathrm{~s}, 2 \mathrm{H}), 3.97(\mathrm{~s}, 2 \mathrm{H}), 3.05$ $(\mathrm{m}, 2 \mathrm{H}), 2.78(\mathrm{~m}, 2 \mathrm{H}), 2.33(\mathrm{~s}, 3 \mathrm{H})$.

Template for SYNTHESIS (C) Thieme Stuttgart · New York 2018-03-28 
${ }^{13} \mathrm{C} \mathrm{NMR}\left(\mathrm{CDCl}_{3}, 100 \mathrm{MHz}\right): \delta=203.5,202.9,167.5,157.3,148.5,139.3$, $135.3,128.5,121.9,69.4,47.2,36.6,30.4,25.4$.

HRMS (EI+): m/z [M+H] ${ }^{+}$calcd for $\mathrm{C}_{14} \mathrm{H}_{13} \mathrm{O}_{4}: 245.0814$; found: 245.0810 .

4-Methyl-5-(2-oxopropyl)-1,3,6,7-tetrahydro-8H-indeno[4,5c]furan-8-one (86)

A microwave vial charged with ((6-(but-2-yn-1-yloxy)-1-(5-methylfuran2-yl)hex-4-yn-3-yl)oxy)(tert-butyl)dimethylsilane (50 mg, $0.14 \mathrm{mmol}$ ), acetonitrile $(4.9 \mathrm{~mL})$ and water $(0.05 \mathrm{~mL})$ was heated to $200{ }^{\circ} \mathrm{C}$ for 5 hours under microwave conditions. The solution was concentrated under reduced pressure and the crude material was purified by column chromatography (7.5\% ethyl acetate in DCM) to give the title compound as a white solid (16 $\mathrm{mg}, 0.065 \mathrm{mmol}, 48 \%$ ).

$\mathrm{R}_{\mathrm{f}}=0.20$ (10\% ethyl acetate in DCM).

IR (neat): 2925, 2850, 1716, 1687, 1602, 1360, 1325, 1161, $1140 \mathrm{~cm}^{-1}$.

${ }^{1} \mathrm{H}$ NMR (400 MHz, $\mathrm{CDCl}_{3}$ ): $\delta=5.40$ and $5.36(\mathrm{t}, J=2.5 \mathrm{~Hz}, 2 \mathrm{H}), 5.09(\mathrm{~m}$, $2 \mathrm{H}), 3.85$ and $3.82(\mathrm{~s}, 2 \mathrm{H}), 3.01(\mathrm{~m}, 2 \mathrm{H}), 2.69(\mathrm{~m}, 2 \mathrm{H}), 2.27$ and $2.26(\mathrm{~s}$, $3 \mathrm{H}), 2.18(\mathrm{~s}, 3 \mathrm{H})$. Some peaks are doubled due to the presence of rotamers.

${ }^{13} \mathrm{C}$ NMR (100 MHz, $\left.\mathrm{CDCl}_{3}\right): \delta=206.5,204.8,154.5,139.6,137.4,135.8$, 130.3, 128.1, $73.973 .1,72.8,72.6,47.3,43.8,36.5,36.3,30.029 .8,25.8$ $25.3,16.9$. Some peaks are doubled due to the presence of rotamers

HRMS (EI+): $m / z$ [M] ${ }^{+}$calcd for $\mathrm{C}_{15} \mathrm{H}_{16} \mathrm{O}_{3}: 244.1094$; found: 244.1103 . 5-(2-0xopropyl)-4-phenyl-1H,3H,6H,7H,8H-indeno[4,5-c]furan-3,8dione (87)

A microwave vial charged with 4-[(tert-butyldimethylsilyl)oxy]-6-(5methylfuran-2-yl)hex-2-yn-1-yl 3- phenylprop-2-ynoate $(50 \mathrm{mg}, 0.11$ mmol), acetonitrile $(4.9 \mathrm{~mL})$ and water $(0.05 \mathrm{~mL})$ was heated to $200{ }^{\circ} \mathrm{C}$ for 2 hours under microwave conditions. The solution was concentrated under reduced pressure. The crude material was purified by column chromatography $(0-50 \%$ ethyl acetate in DCM) to yield the title compound as a colourless oil (24 mg, $0.075 \mathrm{mmol}, 65 \%$ ).

$\mathrm{Rf}=0.52$ (50\% ethyl acetate in DCM).

IR (neat): 2921, 2851, 1760, 1714, 1615, 1359, 1159, 1093, $1014 \mathrm{~cm}^{-1}$.

${ }^{1} \mathrm{H} \mathrm{NMR}\left(\mathrm{CDCl}_{3}, 400 \mathrm{MHz}\right): \delta=7.46(\mathrm{~m}, 3 \mathrm{H}), 7.13(\mathrm{~m}, 2 \mathrm{H}), 5.55(\mathrm{~s}, 2 \mathrm{H})$, $3.71(\mathrm{~s}, 2 \mathrm{H}), 3.12(\mathrm{~m}, 2 \mathrm{H}), 2.81(\mathrm{~m}, 2 \mathrm{H}), 2.07(\mathrm{~s}, 3 \mathrm{H})$.

${ }^{13} \mathrm{C} \mathrm{NMR}\left(\mathrm{CDCl}_{3}, 100 \mathrm{MHz}\right): \delta=205.5,204.7,168.7,161.2,144.2,134.7$, 133.6, 131.2, 129.3, 128.8, 128.5, 127.5, 123.6, 68.3, 44.0, 36.3, 30.2, 26.7. HRMS (EI+): $m / z$ [M+H] ${ }^{+}$calcd for $\mathrm{C}_{20} \mathrm{H}_{17} \mathrm{O}_{4}: 321.1127$; found: 321.1133 .

4-(Naphthalen-1-yl)-5-(2-oxopropyl)-6,7-dihydro-1H-indeno[4,5c]furan-3,8-dione (88)

A microwave vial charged with 4-((tert-butyldimethylsilyl)oxy)-6-(5methylfuran-2-yl)hex-2-yn-1-yl 3-(naphthalen-1-yl) propiolate $(65 \mathrm{mg}$, $0.13 \mathrm{mmol})$, acetonitrile $(4.9 \mathrm{~mL})$ and water $(0.05 \mathrm{~mL})$ was heated to 200 ${ }^{\circ} \mathrm{C}$ for 2 hours under microwave conditions. The solution was concentrated under reduced pressure and the crude material was purified by column chromatography (7.5\% ethyl acetate in DCM) to yield the title compound as a white solid (23 $\mathrm{mg}, 0.062 \mathrm{mmol}, 48 \%$ ).

$\mathrm{R}_{\mathrm{f}}=0.37$ (10\% ethyl acetate in DCM).

IR (neat): 2924, 1763, 1706, 1609, 1358, $1101 \mathrm{~cm}^{-1}$.

${ }^{1} \mathrm{H} \mathrm{NMR}\left(400 \mathrm{MHz}^{\mathrm{CDCl}}\right.$ ) $: \delta=7.96(\mathrm{dd}, J=8.5,1.0 \mathrm{~Hz}, 1 \mathrm{H}), 7.93(\mathrm{~d}, J=$ $8.5 \mathrm{~Hz}, 1 \mathrm{H}), 7.55$ (dd, $J=8.5,7.0 \mathrm{~Hz}, 1 \mathrm{H}), 7.49$ (ddd, $J=8,7,1 \mathrm{~Hz}, 1 \mathrm{H}$ ), 7.34 (ddd, $J=8,7,1.5 \mathrm{~Hz}, 1 \mathrm{H}$ ), 7.19 (dd, $J=7.0,1.0 \mathrm{~Hz}, 1 \mathrm{H}$ ), 7.13 (dd, $J=$ 8.5, $1.0 \mathrm{~Hz}, 1 \mathrm{H}), 5.59$ (d, $J=1.0 \mathrm{~Hz}, 2 \mathrm{H}), 3.61(1 \mathrm{H}, \mathrm{d}, J=17.5 \mathrm{~Hz}), 3.46(1 \mathrm{H}$, $\mathrm{d}, J=17.5 \mathrm{~Hz}), 3.17(\mathrm{~m}, 2 \mathrm{H})), 2.85(\mathrm{~m}, 2 \mathrm{H}), 1.81(\mathrm{~s}, 3 \mathrm{H})$.

${ }^{13} \mathrm{C}$ NMR (100 MHz, $\mathrm{CDCl}_{3}$ ): $\delta=205.6,204.4,168.3,161.5,145.5,144.1$, $134.8,133.4,132.5,131.6,131.4,129.3,128.8,126.8,126.6,126.4,125.3$, $124.9,124.7,68.4,43.8,36.4,30.2,26.7$.

HRMS (ESI+): $m / z \quad[\mathrm{M}+\mathrm{H}]^{+}$calcd for $\mathrm{C}_{24} \mathrm{H}_{19} \mathrm{O}_{4}$ : 371.1283; found: 371.1281.
Dimethyl 8-oxo-5-(2-oxopropyl)-3,6,7,8-tetrahydroas-indacene2,2(1H)-dicarboxylate (92)

Dimethyl 2-(4-(tert-butyldimethylsilyloxy)-6-(5-methylfuran-2-yl)hex-2ynyl)-2-(prop-2-ynyl)malonate $(50 \mathrm{mg}, 0.11 \mathrm{mmol}$ ) was dissolved in dimethylformamide $(2 \mathrm{~mL})$ and heated to $200{ }^{\circ} \mathrm{C}$ for 3 hours in a microwave. The reaction mixture was decanted into water, stirred for 10 minutes, and the organics extracted with diethyl ether. The organic layer was then washed with brine, dried with magnesium sulfate and concentrated. The crude was then purified using flash column chromatography (20-60\% ethyl acetate in petroleum ether) to give the title compound as a pale yellow gum (12 mg, $0.035 \mathrm{mmol}, 32 \%)$.

$\mathrm{Rf}=0.20$ (60\% ethyl acetate in petroleum ether).

IR (neat): 2850, 1730, 1710, 1425, 1255, 1140, $1065 \mathrm{~cm}^{-1}$.

${ }^{1} \mathrm{H} \mathrm{NMR}\left(400 \mathrm{MHz}, \mathrm{CDCl}_{3}\right): \delta=7.23(\mathrm{~s}, 1 \mathrm{H}), 3.91(\mathrm{~s}, 2 \mathrm{H}), 3.76(\mathrm{~s}, 2 \mathrm{H}), 3.74$ (s, 6H), $3.58(\mathrm{~s}, 2 \mathrm{H}), 2.95(\mathrm{~m}, 2 \mathrm{H}), 2.67(\mathrm{~m}, 2 \mathrm{H}), 2.23(\mathrm{~s}, 3 \mathrm{H})$.

${ }^{13} \mathrm{C}$ NMR $\left(125 \mathrm{MHz}, \mathrm{CDCl}_{3}\right): \delta=205.2,172.1,153.6,141.0,137.7,133.4$ $131.2,131.2,60.7,53.2,47.4,39.9,39.1,36.5,29.9,24.9$.

HRMS (EI+): $m / z$ [M+H] $]^{+}$calcd for $\mathrm{C}_{19} \mathrm{H}_{21} \mathrm{O}_{6} 345.1338$; found: 345.1344 .

5-(2-oxopropyl)-2-tosyl-2,3,6,7-tetrahydrocyclopenta[e] isoindol8(1H)-one (93)

$\mathrm{N}$-(4-(tert-butyldimethylsilyloxy)-6-(5-methylfuran-2-yl)hex-2-ynyl)-4methyl- $N$-(prop-2-ynyl)benzene sulfonamide $(0.053 \mathrm{~g}, 0.11 \mathrm{mmol}$ ) was dissolved in acetonitrile ( $2 \mathrm{~mL}$ ) in a microwave vial, subsequently adding a drop of water and purging with nitrogen. The mixture was then heated in the microwave at $195{ }^{\circ} \mathrm{C}$ for 1.5 hours. After removing the solvent, the crude material was purified by column chromatography $(0-5 \%$ ethyl acetate in dichloromethane) to yield a white gum $(13 \mathrm{mg}, 0.034 \mathrm{mmol}$, $32 \%)$.

$\mathrm{Rf}=0.20(10 \%$ ethyl acetate in dichloromethane $)$.

IR (neat): 2924, 1705, 1595, 1344, 1160, $1095 \mathrm{~cm}^{-1}$.

${ }^{1} \mathrm{H}$ NMR (400 MHz, $\left.\mathrm{CDCl}_{3}\right): \delta=7.78(\mathrm{~m}, 2 \mathrm{H}), 7.31(\mathrm{~m}, 2 \mathrm{H}), 7.17(\mathrm{~s}, 1 \mathrm{H})$, $4.84(\mathrm{t}, J=2.5 \mathrm{~Hz}, 2 \mathrm{H}), 4.61(\mathrm{~m}, 2 \mathrm{H}), 3.79(\mathrm{~s}, 2 \mathrm{H}), 2.95(\mathrm{~m}, 2 \mathrm{H}), 2.66(\mathrm{~m}$, $2 \mathrm{H}), 2.39(\mathrm{~s}, 3 \mathrm{H}), 2.25(\mathrm{~s}, 3 \mathrm{H})$.

${ }^{13} \mathrm{C}$ NMR (125 MHz, $\left.\mathrm{CDCl}_{3}\right): \delta=206.1,204.5,154.1,143.8,136.7,133.6$, $133.3,132.4,132.2,129.9,129.3,127.6,52.8,52.8,46.9,36.1,29.9,25.0$, 21.5.

HRMS (EI+): $m / z[M+H]^{+}$calcd for $\mathrm{C}_{21} \mathrm{H}_{22} \mathrm{NO}_{4} \mathrm{~S}$ : 384.1270; found: 384.1279 .

5-(2-0xopropyl)-6,7-dihydro-1 $H$-indeno[4,5-c]thiophen-8(3H)-one (94)

tert-Butyldimethyl(1-(5-methylfuran-2-yl)-6-(prop-2-ynylthio)hex-4-yn3-yloxy)silane (0.05 g, $0.15 \mathrm{mmol})$ was dissolved in acetonitrile (2 $\mathrm{mL})$, in a microwave vial; a drop of water was then added and the mixture purged with nitrogen. The vial was then heated at $200{ }^{\circ} \mathrm{C}$ for 6.5 hours in the microwave. The reaction mixture was then concentrated, and the crude mixture purified using column chromatography $(0-50 \%$ ethyl acetate in petroleum ether) to yield a viscous yellow oil (10 mg, 0.041 mmol, 27\%).

$\mathrm{Rf}=0.35$ (40\% ethyl acetate in petroleum ether).

IR (neat): 2923, 1706, 1584, 1358, $1163 \mathrm{~cm}^{-1}$.

${ }^{1} \mathrm{H} \mathrm{NMR}\left(400 \mathrm{MHz}^{\mathrm{CDCl}} 3\right): \delta=7.28(\mathrm{~s}, 1 \mathrm{H}), 4.57(\mathrm{t}, J=2.5 \mathrm{~Hz}, 2 \mathrm{H}), 4.22$ (m, 2H), 3.79 (s, 2H), $2.98(\mathrm{~m}, 2 \mathrm{H}), 2.69(\mathrm{~m}, 2 \mathrm{H}), 2.25(\mathrm{~s}, 3 \mathrm{H})$.

${ }^{13} \mathrm{C}$ NMR (125 MHz, $\left.\mathrm{CDCl}_{3}\right): \delta=206.9,204.9,153.6,141.8,138.2,133.5$, $131.7,131.1,47.1,36.8,36.6,36.4,29.9,24.7$.

HRMS No accurate mass found by EI+ or CI+.

1-(2,7-Dioxa-4,5,6,8-tetrahydro-as-indacen-4-yl)-2-propanone (100)

2-Methyl-5-((4-(prop-2-ynyloxy)but-2-ynyloxy)methyl)furan $[0.010 \mathrm{~g}$ $0.046 \mathrm{mmol}$ ) was dissolved in acetonitrile $(0.5 \mathrm{~mL})$ in a microwave vial. A drop of water was added, the vial purged with nitrogen, and heated in 
the microwave at $200{ }^{\circ} \mathrm{C}$ for 1 hour. The solvent was removed to yield a yellow gum (10 mg, $0.046 \mathrm{mmol}, 99 \%$ ).

$\mathrm{Rf}=0.35$ (40\% ethyl acetate in petroleum ether)

IR (neat): 2844, 1713, 1362, 1163, $1027 \mathrm{~cm}^{-1}$.

${ }^{1} \mathrm{H} \mathrm{NMR}\left(400 \mathrm{MHz}^{\mathrm{CDCl}} 3\right.$ ): $\delta=7.17(\mathrm{~s}, 1 \mathrm{H}), 7.15(\mathrm{t}, J=1.5 \mathrm{~Hz}, 1 \mathrm{H}), 4.81$ (m, 2H), $4.65(\mathrm{~m}, 2 \mathrm{H}), 3.48(\mathrm{~m}, 1 \mathrm{H}), 2.81$ (dd, $J=17.5,7 \mathrm{~Hz}, 1 \mathrm{H}), 2.63$ (dd, $J=17.5,7 \mathrm{~Hz}, 1 \mathrm{H}), 2.54(\mathrm{~m}, 1 \mathrm{H}), 2.15(\mathrm{~s}, 3 \mathrm{H}), 2.03(\mathrm{~m}, 1 \mathrm{H})$.

${ }^{13} \mathrm{C}$ NMR $\left(125 \mathrm{MHz}, \mathrm{CDCl}_{3}\right): \delta=207.3,137.8,134.9,132.9,124.4,123.5$, $117.2,77.0,74.1,49.3,30.7,27.7,26.1$.

HRMS (CI+): $m / z[\mathrm{M}+\mathrm{H}]^{+}$calcd for $\mathrm{C}_{13} \mathrm{H}_{15} \mathrm{O}_{3}: 219.1021$; found: 219.1020 .

\section{1-(4-Methylfuran-3-yl)propan-2-one (110)}

tert-Butyldimethyl(5-(prop-2-ynyloxy)pent-3-yn-2-yloxy)silane ${ }^{32} \quad$ (55 $\mathrm{mg}, 0.22 \mathrm{mmol}$ ) was dissolved in acetonitrile $(2 \mathrm{~mL})$ in a microwave vial; a drop of water was added and the vial purged with nitrogen. The mixture was heated at $190{ }^{\circ} \mathrm{C}$ in the microwave for 1 hour. After removal of the solvent, the crude mixture was purified using flash column chromatography $(0-50 \%$ ethyl acetate in petrol) to yield the title compound 110 as a pale yellow oil (12 mg, $0.087 \mathrm{mmol}, 40 \%)$ and 111 as a yellow oil ( $5 \mathrm{mg}, 0.036 \mathrm{mmol}, 15 \%)$

$\mathrm{Rf}=0.70$ (50\% ethyl acetate in petrol).

IR (neat): 2928 (C-H), 1716 (C=0), 1361, 1165, $1049 \mathrm{~cm}^{-1}$.

${ }^{1} \mathrm{H}$ NMR (400 MHz): $\delta=7.32-7.31(\mathrm{~m}, 1 \mathrm{H}), 7.21-7.19(\mathrm{~m}, 1 \mathrm{H}), 3.47(\mathrm{~s}$, $2 \mathrm{H}), 2.18(\mathrm{~s}, 3 \mathrm{H}), 1.92-1.92(\mathrm{~d}, \mathrm{~J}=1 \mathrm{~Hz}, 3 \mathrm{H})$.

${ }^{13} \mathrm{C}$ NMR (125 MHz): $\delta=206.0,141.0,140.1,120.1,118.4,38.9,29.2,8.2$. HRMS (EI+): $m / z$ [M] $\mathrm{C}_{8} \mathrm{H}_{10} \mathrm{O}_{2}$ calcd for 138.0681; found: 138.0686 .

\section{1,6,7,7a-Tetrahydroisobenzofuran-5(3H)-one (111)}

A yellow oil (5 mg, $0.036 \mathrm{mmol}, 15 \%)$.

$\mathrm{R}_{\mathrm{f}}=0.15$ (50\% ethyl acetate in petrol)

IR (neat): 2941, 1677, 1667, 1373, 1194, $1051 \mathrm{~cm}^{-1}$.

${ }^{1} \mathrm{H}$ NMR (400 MHz, $\left.\mathrm{CDCl}_{3}\right): \delta=5.94(\mathrm{~m}, 1 \mathrm{H}), 4.69-4.64(\mathrm{dt}, J=16.5,1.5$ $\mathrm{Hz}, 1 \mathrm{H}), 4.47-4.38(\mathrm{dt}, J=16.5,1.5 \mathrm{~Hz}, 1 \mathrm{H}), 4.33-4.29(\mathrm{t}, J=8.5 \mathrm{~Hz}, 1 \mathrm{H})$, 3.38-3.33 (dd, $J=10.5,8.5 \mathrm{~Hz}, 1 \mathrm{H}), 3.02-2.93(\mathrm{~m}, 1 \mathrm{H}), 2.57-2.52(\mathrm{~m}, 1 \mathrm{H})$, 2.42-2.33 (ddd, $J=17,14.5,5 \mathrm{~Hz}, 1 \mathrm{H}$ ), 2.26-2.20 (dtd, $J=12,5,2.5 \mathrm{~Hz}$ 1H), 1.75-1.64 (dddd, $J=14.5,13,11.5,4.5 \mathrm{~Hz}, 1 \mathrm{H}$ ).

${ }^{13} \mathrm{C} \mathrm{NMR}\left(125 \mathrm{MHz} \mathrm{CDCl}_{3}\right): \delta=198.6,168.8,119.9,73.2,69.8,41.7,36.7$, 25.6.

HRMS (EI+): $m / z$ [M] calcd for $\mathrm{C}_{8} \mathrm{H}_{10} \mathrm{O}_{2}: 138.0681$; found: 138.0686 .

\section{1-(4-Methylthiophen-3-yl)propan-2-one (120)}

tert-Butyldimethyl(5-(prop-2-ynylthio)pent-3-yn-2-yloxy)silane $(50 \mathrm{mg}$, $0.19 \mathrm{mmol}$ ) was dissolved in acetonitrile $(2 \mathrm{~mL})$ in a microwave vial. A drop of water was added, the vial purged with nitrogen, and the mixture heated in the microwave for 6 hours at $200^{\circ} \mathrm{C}$. The solvent was removed and the crude mixture purified by flash chromatography $(20 \%$ ethyl acetate in petrol) to yield the title compound 120 as a yellow gum (6 mg, $0.039 \mathrm{mmol}, 21 \%$ ).

$\mathrm{Rf}=0.40(20 \%$ ethyl acetate in petrol $)$.

IR (neat): 2927, 1709, 1356, 1158, $1100 \mathrm{~cm}^{-1}$.

${ }^{1} \mathrm{H}$ NMR (400 MHz, $\left.\mathrm{CDCl}_{3}\right): \delta=7.07-7.06(\mathrm{~d}, J=3.5 \mathrm{~Hz}, 1 \mathrm{H}), 6.96-6.94(\mathrm{~m}$, $1 \mathrm{H}), 3.64(\mathrm{~s}, 2 \mathrm{H}), 2.15(\mathrm{~s}, 3 \mathrm{H}), 2.14-2.14(\mathrm{~d}, J=1 \mathrm{~Hz}, 3 \mathrm{H})$.

${ }^{13} \mathrm{C}$ NMR $\left(125 \mathrm{MHz} \mathrm{CDCl}_{3}\right): \delta=206.0,137.1,134.1,123.7,122.0,44.4$, 29.3, 14.6 .

HRMS (CI+): $m / z\left[\mathrm{M}+\mathrm{NH}_{4}\right]^{+}$calcd for $\mathrm{C}_{8} \mathrm{H}_{14} \mathrm{NOS}$ : 172.0796; found: 172.0799

\section{8-Thiabicyclo[4.3.0]non-1-en-3-one (121)}

tert-Butyldimethyl(5-(prop-2-ynylthio)pent-3-yn-2-yloxy)silane $(0.20 \mathrm{~g}$, $0.74 \mathrm{mmol}$ ) was dissolved in acetonitrile $(4 \mathrm{~mL})$ in a microwave vial. 2 drops of water were added, the vial purged with nitrogen, and the mixture heated in the microwave for 6 hours at $200{ }^{\circ} \mathrm{C}$. The solvent was removed and the crude mixture purified by flash column chromatography (10-20\% ethyl acetate in petrol) to yield a pale yellow to yellow gum (13 mg, $0.084 \mathrm{mmol}, 11 \%$ ).

$\mathrm{R}_{\mathrm{f}}=0.15$ (20\% ethyl acetate in petrol).

IR (neat): 2926, 1664, 1321, 1251, $1194 \mathrm{~cm}^{-1}$.

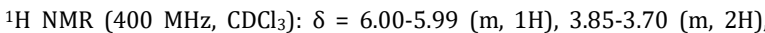
3.17- 3.12 (dd, $J=11,7.5 \mathrm{~Hz}, 1 \mathrm{H}), 3.06-2.97(\mathrm{~m}, 1 \mathrm{H}), 2.69-2.63(\mathrm{t}, J=10.5$ $\mathrm{Hz}, 1 \mathrm{H}), 2.55-2.48(\mathrm{~m}, 1 \mathrm{H}), 2.40-2.31(\mathrm{~m}, 2 \mathrm{H}), 1.82-1.71(\mathrm{~m}, 1 \mathrm{H})$.

${ }^{13} \mathrm{C}$ NMR $\left(125 \mathrm{MHz}, \mathrm{CDCl}_{3}\right): \delta=198.9,168.3,123.6,45.2,36.8,36.4,35.8$ 28.8.

HRMS (CI+): $m / z\left[M+\mathrm{NH}_{4}\right]^{+}$calcd for $\mathrm{C}_{8} \mathrm{H}_{14} \mathrm{NOS}$ : 172.0796; found: 172.0794 .

\section{1-(4-Methyl-1-tosyl-1H-pyrrol-3-yl)propan-2-one (125)}

$N$-(4-(tert-Butyldimethylsilyloxy)pent-2-ynyl)-4-methyl- $N$-(prop-2-ynyl) benzenesulfonamide $(60 \mathrm{mg}, 0.15 \mathrm{mmol}$ ) was dissolved in acetonitrile (2 $\mathrm{mL}$ ) in a microwave vial. A drop of water was added, the vial purged with nitrogen, and then heated in the microwave at $200{ }^{\circ} \mathrm{C}$ for 1.5 hours. The solvent was removed and the crude mixture purified by flash column chromatography (5-50\% ethyl acetate in petrol) to yield the title compound 125 as a white to yellow gum (18 mg, $0.062 \mathrm{mmol}, 41 \%$ ), along with 126 and 127.

$\mathrm{R}_{\mathrm{f}}=0.20$ (20\% ethyl acetate in petrol).

IR (neat): 2919, 1713, 1595, 1364, 1169, $1064 \mathrm{~cm}^{-1}$.

${ }^{1} \mathrm{H}$ NMR (400 MHz, $\left.\mathrm{CDCl}_{3}\right): \delta=7.72-7.70(\mathrm{~m}, 2 \mathrm{H}), 7.30-7.28(\mathrm{~m}, 2 \mathrm{H})$, 7.02-7.02 (d, $J=2 \mathrm{~Hz}, 1 \mathrm{H}), 6.89-6.88(\mathrm{~m}, 1 \mathrm{H}), 3.41(\mathrm{~s}, 2 \mathrm{H}), 2.39(\mathrm{~s}, 3 \mathrm{H})$ $2.11(\mathrm{~s}, 3 \mathrm{H}), 1.90-1.89(\mathrm{~d}, J=1 \mathrm{~Hz}, 3 \mathrm{H})$.

${ }^{13} \mathrm{C}$ NMR $\left(125 \mathrm{MHz}, \mathrm{CDCl}_{3}\right): \delta=205.9,144.9,136.3,130.1,126.9,124.3$ $121.8,119.5,118.5,40.7,29.2,21.8,10.4$.

HRMS (ES+): $m / z[M+H]^{+}$calcd for $\mathrm{C}_{15} \mathrm{H}_{18} \mathrm{NO}_{3} \mathrm{~S}$ : 292.1002; found: 292.1010 .

\section{2-Tosyl-1,2,3,6,7,7a-hexahydroisoindol-5-one (126)}

Pale yellow to yellow gum (7 mg, $0.024 \mathrm{mmol}, 16 \%)$.

$\mathrm{R}_{\mathrm{f}}=0.25$ (50\% ethyl acetate in petrol).

IR (neat): 2933, 1670, 1595, 1345, 1162, $1094 \mathrm{~cm}^{-1}$.

${ }^{1} \mathrm{H}$ NMR (400 MHz, $\left.\mathrm{CDCl}_{3}\right): \delta=7.73-7.71(\mathrm{~m}, 2 \mathrm{H}), 7.37-7.35(\mathrm{~d}, J=8 \mathrm{~Hz}$ $2 \mathrm{H}), 5.88-5.87(\mathrm{~m}, 1 \mathrm{H}), 4.33-4.27(\mathrm{dt}, J=17,1.5 \mathrm{~Hz}, 1 \mathrm{H}), 3.94-3.90(\mathrm{~m}$, $1 \mathrm{H}), 3.83-3.79$ (dt, $J=17,2 \mathrm{~Hz}, 1 \mathrm{H}), 2.98-2.89(\mathrm{~m}, 1 \mathrm{H}), 2.66-2.61$ (dd, $J=$ $11,9.5 \mathrm{~Hz}, 1 \mathrm{H}), 2.49-2.45(\mathrm{~m}, 1 \mathrm{H}), 2.45(\mathrm{~s}, 3 \mathrm{H}), 2.34-2.25$ (ddd, $J=17$, $14.5,5 \mathrm{~Hz}, 1 \mathrm{H}$ ), 2.22-2.16 (dtd, $J=12.5,5,2.5 \mathrm{~Hz}, 1 \mathrm{H}$ ), 1.64-1.53 (dddd, $J$ $=14.5,13,11.5,4.5 \mathrm{~Hz}, 1 \mathrm{H})$.

${ }^{13} \mathrm{C}$ NMR (125 MHz, $\left.\mathrm{CDCl}_{3}\right): \delta=197.7,164.0,144.3,132.8,130.1,127.9$, $122.5,53.2,51.3,40.5,36.5,26.7,21.7$.

\section{2-Tosyl-2,3,6,7-tetrahydro-1H-isoindol-5(4H)-one (127)}

Pale yellow to yellow gum (6 mg, $0.021 \mathrm{mmol}, 14 \%)$.

$\mathrm{R}_{\mathrm{f}}=0.30$ (50\% ethyl acetate in petrol).

IR (neat): 2921, 1713, 1595, 1341, 1160, $1100 \mathrm{~cm}^{-1}$.

${ }^{1} \mathrm{H}$ NMR (400 MHz, $\left.\mathrm{CDCl}_{3}\right): \delta=7.74-7.72(\mathrm{~m}, 2 \mathrm{H}), 7.35-7.33(\mathrm{~d}, J=8 \mathrm{~Hz}$, $2 \mathrm{H}), 4.08(\mathrm{~s}, 2 \mathrm{H}), 4.04(\mathrm{~s}, 2 \mathrm{H}), 2.77(\mathrm{~s}, 2 \mathrm{H}), 2.52-2.49(\mathrm{t}, J=7 \mathrm{~Hz}, 2 \mathrm{H})$ $2.44(\mathrm{~s}, 3 \mathrm{H}), 2.40-2.36(\mathrm{~m}, 2 \mathrm{H})$.

${ }^{13} \mathrm{C}$ NMR $\left(125 \mathrm{MHz}, \mathrm{CDCl}_{3}\right): \delta=207.4,143.8,134.3,130.3,130.0,128.3$, 127.6, 56.6, 56.5, 37.9, 23.1, 21.7.

\section{6,7-Dihydro-1H-cyclopenta[d]furo[3,4-b]pyridin-8(3H)-one}

\section{(129)}

2-(4-(tert-Butyldimethylsilyloxy)-6-(5-methylfuran-2-yl)hex-2ynyloxy)acetonitrile ( $42 \mathrm{mg}, 0.12 \mathrm{mmol}$ ) was dissolved in acetonitrile (2 $\mathrm{mL}$ ) in a microwave vial. A drop of water was added, and then the vial was purged with nitrogen. The mixture was heated at $200{ }^{\circ} \mathrm{C}$ in the microwave for 6 hours. The solvent was then removed and the crude mixture purified by flash chromatography $(0-40 \%$ ethyl acetate in dichloromethane) to yield a pale yellow gum ( $8 \mathrm{mg}, 0.046 \mathrm{mmol}, 42 \%$ ). 
$\mathrm{R}_{\mathrm{f}}=0.35$ (40\% ethyl acetate in dichloromethane).

IR (neat): 2900, 1995, 1710, 1395, $1025 \mathrm{~cm}^{-1}$.

${ }^{1} \mathrm{H}$ NMR (400 MHz, CDCl $): \delta=8.78(\mathrm{~s}, 1 \mathrm{H}), 5.40(\mathrm{~m}, 2 \mathrm{H}), 5.10(\mathrm{~m}, 2 \mathrm{H})$, $3.27(\mathrm{~m}, 2 \mathrm{H}), 2.76(\mathrm{~m}, 2 \mathrm{H})$.

${ }^{13} \mathrm{C}$ NMR $\left(125 \mathrm{MHz}, \mathrm{CDCl}_{3}\right): \delta=206.9,160.7,149.4,146.4,138.0,128.0$, $72.2,71.7,36.3,24.3$.

HRMS (ESI+): $m / z[\mathrm{M}+\mathrm{H}]^{+}$calcd for $\mathrm{C}_{10} \mathrm{H}_{10} \mathrm{NO}_{2}$ : 176.0712 ; found: 176.0718 .

(E)-4-Amino-3-(5-oxo-2-(3-oxobut-1-en-1-yl)cyclopent-1-en-1yl)furan-2(5H)-one (132)

A microwave vial charged with cyanomethyl 4-(tertbutyldimethylsilyloxy)-6-(5-methylfuran-2-yl)hex-2-ynoate (50 mg, 0.14 mmol), acetonitrile $(4.9 \mathrm{~mL})$ and water $(0.05 \mathrm{~mL})$ was heated to $200{ }^{\circ} \mathrm{C}$ for 5 hours under microwave conditions. The solution was concentrated under reduced pressure and the crude material was purified by column chromatography $(0-50 \%$ ethyl acetate in DCM) to give the title compound as a colourless oil (21 mg, $0.086 \mathrm{mmol}, 62 \%)$.

$\mathrm{R}_{\mathrm{f}}=0.27$ (5\% MeOH in DCM).

IR (neat): 2918, 2850, 1724, 1263, $1098 \mathrm{~cm}^{-1}$.

${ }^{1} \mathrm{H}$ NMR (400 MHz, DMSO- $d_{6}$ ): $\delta=7.45(\mathrm{~d}, J=16.0 \mathrm{~Hz}, 1 \mathrm{H}), 7.26$ (br. s, $2 \mathrm{H}), 6.57(\mathrm{~d}, J=16.0 \mathrm{~Hz}, 1 \mathrm{H}), 4.73(\mathrm{~s}, 2 \mathrm{H}), 2.77(\mathrm{~m}, 2 \mathrm{H}), 2.47(\mathrm{~m}, 2 \mathrm{H})$, $2.29(\mathrm{~s}, 3 \mathrm{H})$

${ }^{13} \mathrm{C}$ NMR (100 MHz, DMSO- $\left.d_{6}\right): \delta=206.6,198.1,172.6,167.1,161.7$, $137.8,136.8,130.8,84.1,66.6,33.9,27.8,25.6$.

HRMS (ESI-): $m / z$ [M-H] $]^{-}$calcd for $\mathrm{C}_{13} \mathrm{H}_{12} \mathrm{NO}_{4}$ : 246.0766; found: 246.0771.

Cyanomethyl (syn-1-anti-3,6)-1-((tert-butyldimethylsilyl)oxy)-6methyl-1,2,3,6-tetrahydro-3a,6-epoxyindene-7-carboxylate (133)

Cyanomethyl 4-(tert-butyldimethylsilyloxy)-6-(5-methylfuran-2-yl)hex2-ynoate ( $40 \mathrm{mg}, 0.11 \mathrm{mmol}$ ) allowed to stand under $\mathrm{N}_{2}$ for 10 days. The product was obtained as a white crystalline solid $(40 \mathrm{mg}, 0.11 \mathrm{mmol}$, $100 \%)$

$\mathrm{R}_{\mathrm{f}}=0.17$ (10\% ethyl acetate in pentane).

$\mathrm{MP}=87-90^{\circ} \mathrm{C}$; Decomposition

IR (neat): 2930, 2238, 1720, 1253, 1087, 1057, $838 \mathrm{~cm}^{-1}$.

${ }^{1} \mathrm{H}$ NMR (400 MHz, $\left.\mathrm{CDCl}_{3}\right): \delta=6.90(\mathrm{~d}, J=5.0 \mathrm{~Hz}, 1 \mathrm{H}), 6.8(\mathrm{~d}, J=5.0 \mathrm{~Hz}$, 1H), $5.0(\mathrm{~m}, 1 \mathrm{H}), 4.8(\mathrm{~s}, 2 \mathrm{H}), 2.5(\mathrm{~m}, 1 \mathrm{H}), 2.2(\mathrm{~m}, 2 \mathrm{H}), 2.0(\mathrm{~m}, 1 \mathrm{H}), 1.9(\mathrm{~s}$, $3 \mathrm{H}), 0.8(\mathrm{~s}, 9 \mathrm{H}), 0.1(\mathrm{~s}, 3 \mathrm{H}),-0.1(\mathrm{~s}, 3 \mathrm{H})$.

${ }^{13} \mathrm{C}$ NMR (100 MHz, $\left.\mathrm{CDCl}_{3}\right): \delta=181.1,161.8,146.0,145.1,135.7,114.4$, $99.4,95.6,67.6,48.2,39.0,25.7,24.7,18.2,17.2,-4.7,-5.0$.

HRMS (CI+): $m / z[M+H]^{+}$calcd for $\mathrm{C}_{19} \mathrm{H}_{28} \mathrm{NO}_{4} \mathrm{Si}$ : 362.1788; found: 362.1782 .

\section{Funding Information}

A Parsons Scholarship was received by J.A.P and L.A.T.A, with further funding from Drs Bader (L.A.T.A) and Anacor (J.A.P). An Imperial College PhD Scholarship funded work completed by D.R.J. (EPSRC: 1507589). We also gratefully acknowledge the Bader scholarship received by A.C.P.

\section{Acknowledgment}

Dr. Alfred Bader is a highly successful business man and a scholar in many fields including art and the chemical sciences. He founded the Sigma Aldrich chemical company and has been over the years an outstandingly generous philanthropist. His support and investment in the chemical sciences alone has led to really outstanding discoveries together with the training of the next generation of top scientists. This paper is dedicated to Dr. Alfred Bader who is now 93 years old and also to his wonderful wife Isabel who has supported and collaborated with Alfred in the areas of art scholarship and helping to generate highly successful chemists and scientists. ${ }^{33}$
We would also like to acknowledge Peter Haycock, Dick Shepherd, Lisa Haigh and Andrew White for their help with NMR, mass spectrometry, and X-ray crystallography.

\section{Supporting Information}

YES (this text will be updated with links prior to publication)YES (this text will be updated with links prior to publication)

\section{Primary Data}

NO (this text will be deleted prior to publication)NO (this text will be deleted prior to publication)

\section{References}

(1) Nicolaou, K. C.; Edmonds, D. J.; Bulger, P. G. Angew. Chemie Int. Ed. 2006, 45, 7134

(2) Tietze, L. F. Chem. Rev. 1996, 96, 115.

(3) Tietze, L. F.; Beifuss, U. Angew. Chemie Int. Ed. 1993, 32, 131.

(4) (a) Winkler, J. D.; Axten, J. M. J. Am. Chem. Soc. 1998, 120, 6425. (b) Boto, A.; Freire, R.; Hernández, R.; Suárez, E.; Rodríguez, M. S. J. Org. Chem. 1997, 62, 2975. (c) Tietze, L.-F. Angew. Chemie Int. Ed. 1983, 22, 828. (d) Penkett, C. S.; Woolford, J. A.; Day, I. J.; Coles, M. P. J. Am. Chem. Soc. 2010, 132, 4.

(5) (a) Crimmins, M. T.; Wang, Z.; McKerlie, L. A. J. Am. Chem. Soc. 1998, 120, 1747. (b) Parker, K. A.; Fokas, D. J. Am. Chem. Soc. 1992, 114, 9688. (c) Curran, D. P.; Chen, M.-H. Tetrahedron Lett. 1985, 26, 4991. (d) Parsons, P. J.; Ozlu, Y.; Cladingboel, D. E. Synlett 1993, 357. (e) Nicolaou, K. C.; Roecker, A. J.; Monenschein, H.; Guntupalli, P.; Follmann, M. Angew. Chemie Int. Ed. 2003, 42, 3637.

(6) (a) Pfeiffer, M. W. B.; Phillips, A. J. J. Am. Chem. Soc. 2005, 127, 5334. (b) Sugihara, T.; Coperet, C.; Owczarczyk, Z.; Harring, L. S.; Negishi, E. J. Am. Chem. Soc. 1994, 116, 7923. (c) Cordonnier, M.-C. A.; Jennifer Kan, S. B.; Anderson, E. A. Chem. Commun. 2008, 33, 5818. (d) Trost, B. M.; Shi, Y. J. Am. Chem. Soc. 1991, 113, 701. (e) Maddaford, S. P.; Andersen, N. G.; Cristofoli, W. A.; Keay, B. A. J. Am. Chem. Soc. 1996, 118 10766. (f) Tokan, W. M.; Meyer, F. E.; Schweizer, S.; Parsons, P. J.; de Meijere, A. European J. Org. Chem. 2008, $2008,6152$. (g) Schweizer, S.; Tokan, W. M.; Parsons, P. J.; de Meijere, A. European J. Org. Chem. 2010, 2010, 4687.

(7) (a) Grondal, C.; Jeanty, M.; Enders, D. Nat. Chem. 2010, 2, 167. (b) Mukaiyama, T.; Ishikawa, H.; Koshino, H.; Hayashi, Y. Chem. - A Eur. J. 2013, 19, 17789. (c) Enders, D.; Hüttl, M. R. M.; Grondal, C.; Raabe, G. Nature 2006, 441, 861. (d) Jones, S. B.; Simmons, B.; Mastracchio, A.; Macmillan, D. W. C. Nature 2011, 475 .

(8) (a) Reber, K. P.; Tilley, S. D.; Carson, C. A.; Sorensen, E. J. J. Org Chem. 2013, 78, 9584. (b) Scott, L. T.; Boorum, M. M.; McMahon, B. J.; Hagen, S.; Mack, J.; Blank, J.; Wegner, H.; de Meijere, A. Science 2002, 295, 1500. (c) Harrowven, D. C.; Pascoe, D. D.; Demurtas, D.; Bourne, H. O. Angew. Chemie Int. Ed. 2005, 44, 1221.

(9) Parsons, P. J.; Board, J.; Faggiani, D.; Hitchcock, P. B.; Preece, L.; Waters, A. J. Tetrahedron 2010, 66, 6526.

(10) Parsons, P.; Board, J.; Waters, A.; Hitchcock, P.; Wakenhut, F.; Walter, D. Synlett 2006, 2006, 3243.

(11) Corey, E. J.; Danheiser, R. L.; Chandrasekaran, S.; Keck, G. E.; Gopalan, B.; Larsen, S. D.; Siret, P.; Gras, J. L. J. Am. Chem. Soc. 1978, 100, 8034.

(12) Parsons, P. J.; Jones, D. R.; Walsh, L. J.; Allen, L. A. T.; Onwubiko, A.; Preece, L.; Board, J.; White, A. J. P. Org. Lett. 2017, 19, 2533.

(13) Krasovskiy, A.; Krasovskaya, V.; Knochel, P. Angew. Chemie Int. Ed. 2006, 45, 2958

(14) Parsons, P. J.; Waters, A. J.; Walter, D. S.; Board, J. J. Org. Chem. 2007, 72, 1395. 
(15) (a) Lidström, P.; Tierney, J.; Wathey, B.; Westman, J. Tetrahedron 2001, 57, 9225. (b) Gabriel, C.; Gabriel, S.; Grant, E. H.; Halstead, B. S. J.; Michael, D.; Mingos, P. Chem. Soc. Rev. 1998, 27. (c) Kappe, C. O.; Dallinger, D.; Murphree, S. S. Practical microwave synthesis for organic chemists: strategies, instruments, and protocols; Wiley-VCH, 2009

(16) (a) Hoffmann, H. M. R. Angew. Chemie Int. Ed., 1969, 8, 556. (b) Snider, B. B.; Ron, E. J. Am. Chem. Soc. 1985, 107, 8160.

(17) Domingo, L. R.; Aurell, M. J.; Pérez, P. Org. Biomol. Chem. 2014, $12,7581$.

(18) (a) Schmittel, M.; Strittmatter, M.; Kiau, S. Tetrahedron Lett. 1995, 36, 4975. (b) Schmittel, M.; Strittmatter, M.; Kiau, S. Angew. Chemie Int. Ed. 1996, 35, 1843.

(19) Musch, P. W.; Engels, B. J. Am. Chem. Soc. 2001, 123, 5557.

(20) Bekele, T.; Christian, C. F.; Lipton, M. A.; Singleton, D. A. J. Am. Chem. Soc. 2005, 127, 9216

(21) Ess, D. H.; Wheeler, S. E.; Iafe, R. G.; Xu, L.; Çelebi-Ölçüm, N.; Houk, K. N. Angew. Chemie Int. Ed. 2008, 47, 7592.

(22) Schmittel, M.; Vavilala, C. J. Org. Chem. 2005, 70, 4865.

(23) Schmittel, M.; Vavilala, C.; Jaquet, R. Angew. Chem. Int. Ed. 2007, 46, 6911 .

(24) (a) Peña, D.; Pérez, D.; Guitián, E.; Castedo, L. European J. Org. Chem. 2003, 1238. (b) González, I.; Pla-Quintana, A.; Roglans, A.; Dachs, A.; Solà, M.; Parella, T.; Farjas, J.; Roura, P.; Lloveras, V.; Vidal-Gancedo, J. Chem. Commun. 2010, 46, 2944.
(25) (a) Robinson, J. M.; Sakai, T.; Okano, K.; Kitawaki, T.; Danheiser, R. L. J. Am. Chem. Soc. 2010, 132, 11039. (b) Sakai, T.; Danheiser, R. L. J. Am. Chem. Soc. 2010, 132, 13203.

(26) Parsons, P. J.; Demircan, A. Synlett 1998, 1215.

(27) Annis, M. C. Free radical cascade reactions involving furan rings, Univeristy of Sussex, 2002.

(28) El Kaïm, L.; Grimaud, L.; Wagschal, S.; Oble, J.; Tymoschenko, M.; Sugawara, T. Chem. Commun. 2011, 47, 1887.

(29) (a) Trushkov, I. V.; Uchuskin, M. G.; Butin, A. V. European J. Org. Chem. 2015, 2999. (b) Yin, B.; Cai, C.; Zeng, G.; Zhang, R.; Li, X.; Jiang, H. Org. Lett. 2012, 14, 1098.

(30) Parsons, P. J.; Jones, D. R.; Padgham, A. C.; Allen, L. A. T. Penkett, C. S.; Green, R. A.; White, A. J. P. Chem. - A Eur. J. 2016, 22, 3981.

(31) Banjoko, 0. O. A Novel Cyclisation in the Construction of Fused Rings. Ph.D Thesis, University of Sussex, 2011.

(32) Mukherjee, P.; Widenhoefer, R. A. Angew. Chemie Int. Ed. 2012, 51, 1405-1407

(33) (a) Baykoucheva, S. Chem. Inf. Bull. 2007, 59, 10 (b) Wang, L. Chem. Eng. News, 2014, 92, 17, 34

\section{Biosketches}

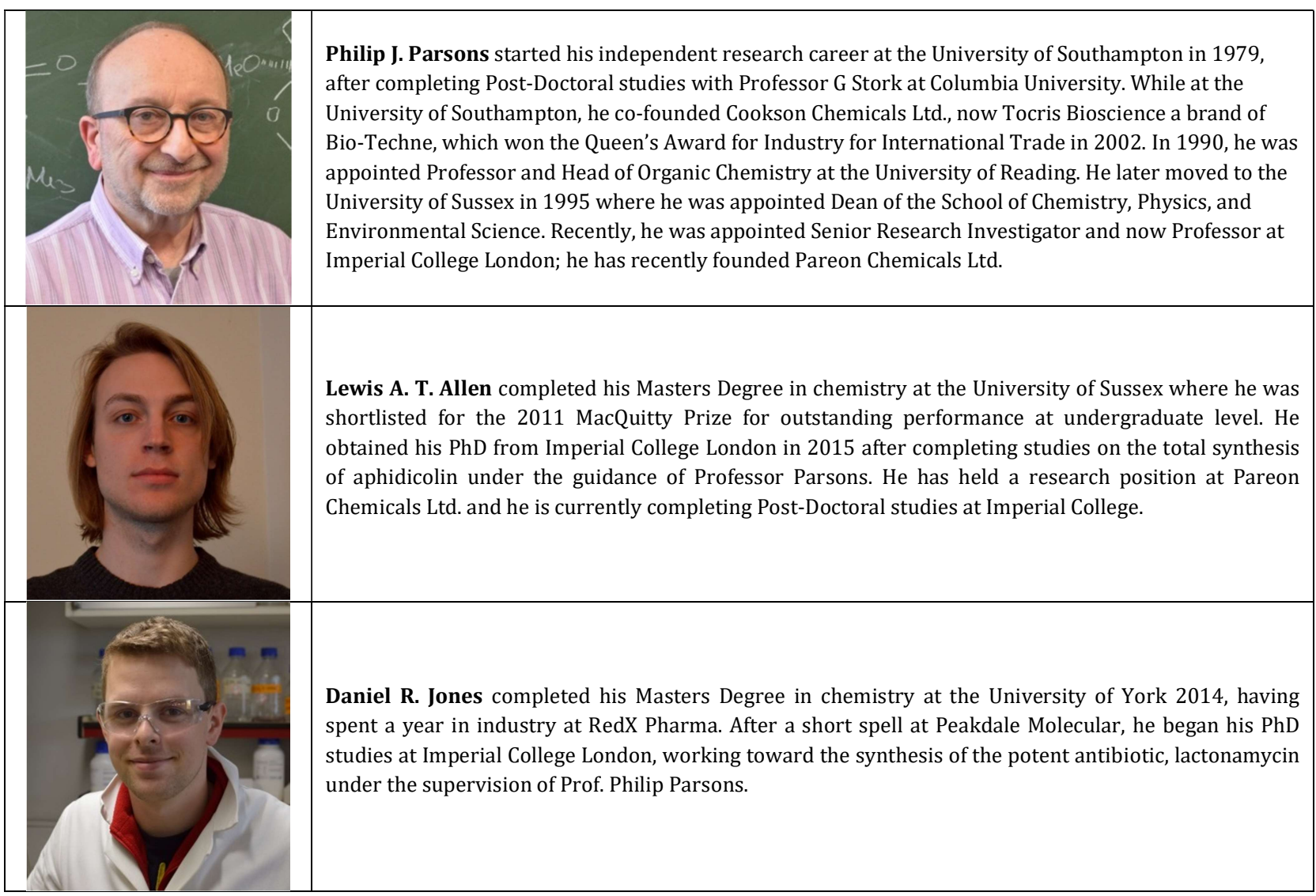




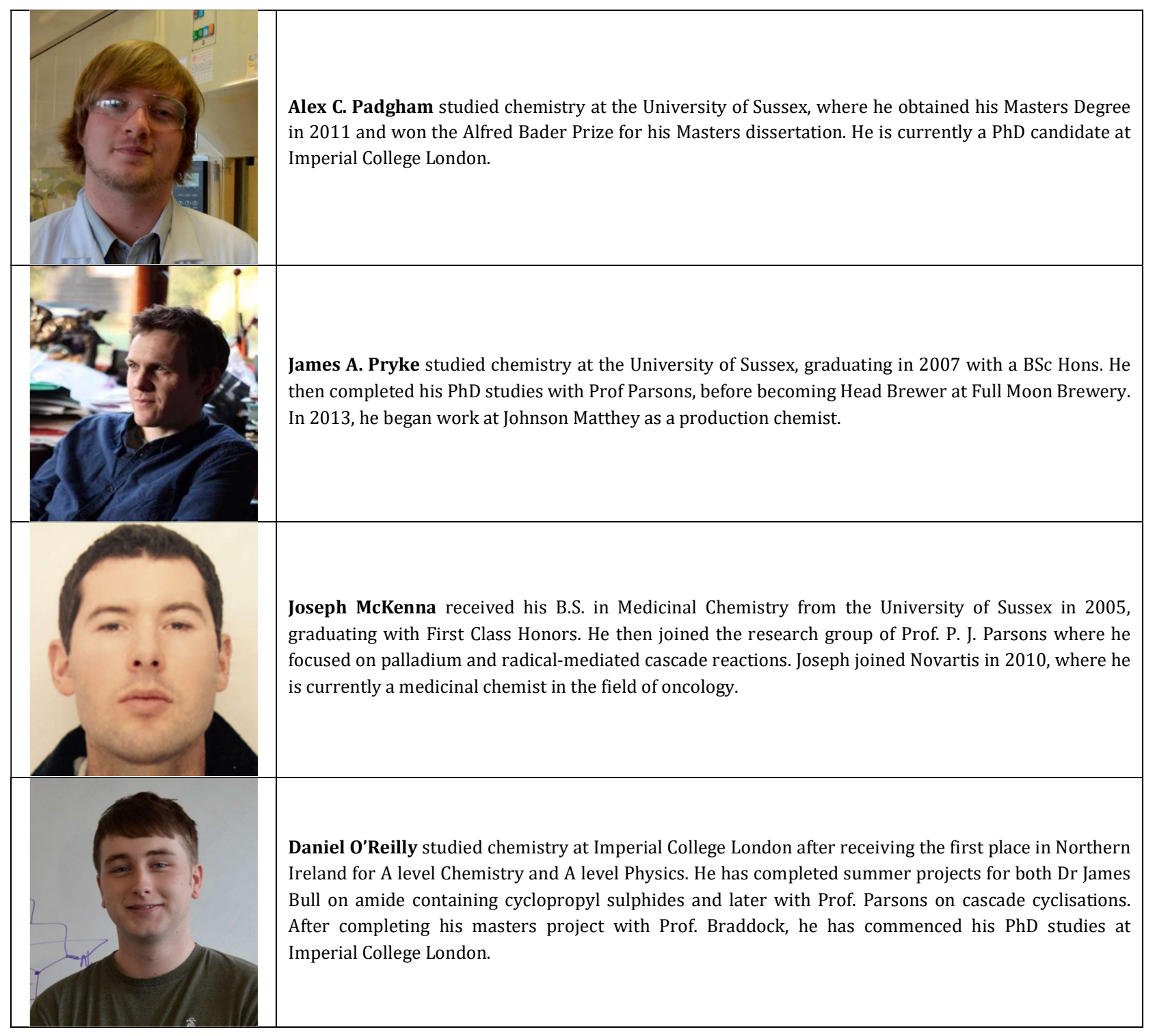

Photographs (.jpg or .tif format) must be a minimum of $300 \mathrm{dpi}$ in order to reproduce well in print. 